\title{
Understanding arsenic metabolism through spectroscopic determination of arsenic in human urine
}

\author{
Eid I. Brima, Richard O. Jenkins and Parvez I. Haris * \\ Faculty of Health and Life Sciences, The School of Allied Health Sciences, De Montfort University, \\ The Gateway, Leicester, LE1 9BH, UK
}

\begin{abstract}
In this review we discuss a range of spectroscopic techniques that are currently used for analysis of arsenic in human urine for understanding arsenic metabolism and toxicity, especially in relation to genetics/ethnicity, ingestion studies and exposure to arsenic through drinking water and diet. Spectroscopic techniques used for analysis of arsenic in human urine include inductively coupled plasma mass spectrometry (ICP-MS), hydride generation atomic absorption spectrometry (HG-AAS), hydride generation atomic fluorescence spectrometry (HG-AFS), graphite furnace atomic absorption spectrometry (GF-AAS) and liquid chromatography mass spectrometry (LC-MS). Advantages and disadvantages of each of these techniques are highlighted in relation to analysis of total arsenic and speciation of arsenic compounds in human urine which would be of particular benefit to those new to the field of arsenic speciation of urine samples. The review summarises our current understanding of arsenic metabolism through the analysis of urine samples and provides a list of arsenic species that have been identified in urine samples. This is done by focusing on recent published reports on arsenic metabolism and toxicity in relation to most investigated issues, i.e. genetics/ethnicity, ingestion and exposure.
\end{abstract}

Keywords: Urine, arsenic, spectroscopic techniques

\section{Introduction}

The need for fast and reliable (spectroscopic) methods for analysis of arsenic (As) in biological samples is obvious from the fact that millions of people worldwide suffer from chronic exposure to inorganic As in their drinking water [1]. In Bangladesh and India alone over 100 million people are affected [2]. As exists in various organic and inorganic forms. Exposure to inorganic As is associated with various health effects such as cancer of skin, lung, kidney, liver and bladder; skin manifestations such as melanosis and keratosis have also been reported [3]. Urinary excretion is the major pathway for the elimination of As compounds from the human body [4]. Therefore, urinary As can be used as a biomarker of exposure to As in humans.

This review provides a basic background theory to each of the spectroscopic techniques that are commonly used for detecting As in human urine and then gives examples of their application in the analysis of As in human urine. Advantages and disadvantages of each technique are discussed in light of studies

\footnotetext{
*Corresponding author. pharis@dmu.ac.uk.
} 
Table 1

Relevant structures, formulae and molecular weights for commonly occurring arsenic containing compounds found in food and the environment and also detected in human urine

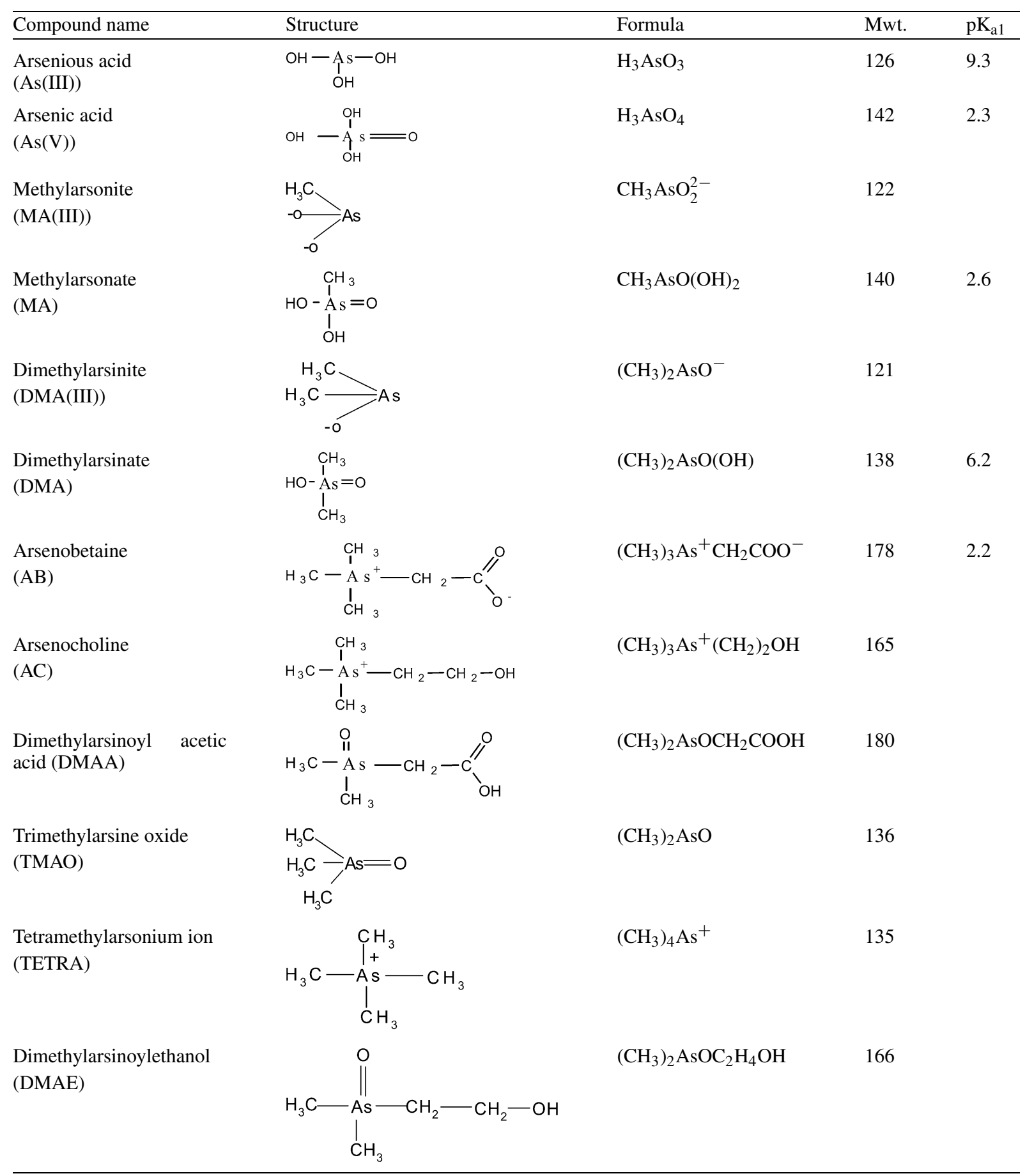


reported in the literature. The examples of studies described fall within three main fields, which are: (i) genetics/ethnicity (the role of genetic polymorphism and ethnicity in relation to As metabolism); (ii) experimental ingestion studies (the effect of ingesting specific food types - e.g. seafood and seaweed - on urinary As); and (iii) exposure to As (environmental and occupational exposure; background level was also covered in this field, which is considered as dietary exposure).

The main objective of this review was to consider recent published reports of As analysis in human urine that use different spectroscopic techniques. It provides an overview of the spectroscopic techniques currently used for As analysis in human urine and the associated procedures used for such analysis; advantages and disadvantages of each of the spectroscopic techniques are highlighted. For comprehensive details readers are directed to previously published articles, books and detailed reviews.

\subsection{Arsenic metabolism - Brief summary}

The toxicity of various As compounds in increasing order are as follows, $\mathrm{AB}<\mathrm{DMA}<\mathrm{MA}<\mathrm{As}(\mathrm{V})$ $<$ As(III), with corresponding LD $_{50}$ values $(\mathrm{mg} / \mathrm{kg}$ ) in rats of, $>10000,700-2600,700-1800,20$ and 14, respectively [5]. Table 1 gives structures and abbreviations of different As species. As species such as As(III), As(V), MA and DMA, which are present in natural waters [6], are more toxic than others which are found in seafood (AB, AC, tetramethylarsonium ion (TETRA) and arsenosugars) [3,7]. Inorganic As species (As(III) and $\mathrm{As}(\mathrm{V}))$ undergo methylation in the human body after ingestion and the major route for elimination of As is urinary excretion [4]. Since the chemical form of As determines its toxicity, it is usually not sufficient to just determine the total level of As in urine, i.e. speciation analysis is important.

Methylation of As in humans is generally thought to involve alternating reduction and oxidative methylation steps. Different methylated arsenic compounds are formed as shown in Fig. 1, which describes the methylation process as suggested by Challenger [8]. However, Hayakawa et al. [9] recently reported that metabolism of As(III) to MA and DMA can take place through a new metabolic pathway, involving arsenic methyltransferase (Cyt19) and via arsenic triglutathione (ATG) and monomethylarsonic diglutathione (MADG), instead of oxidative methylation of As(III) and MA(III) via the Challenger pathway. The authors suggested that ATG can be generated non-enzymatically from As(III) in the presence of glutathione (GSH). Subsequently, the methylation of As is catalyzed by Cyt 19 involving transfer

Table 1

(Continued)

\begin{tabular}{llll}
\hline Compound name & Structure & Formula & Mwt. \\
\hline $\begin{array}{l}\text { Arsenosugars: } \\
\text { Dimethylarsinoylriboside } \\
\text { derivatives }\end{array}$ & & $311+\mathrm{X}$ \\
Arsenosugars: & & \\
Trimethylarsonioriboside \\
derivatives
\end{tabular}




$$
\begin{aligned}
& \mathrm{As}(\mathrm{OH})_{3} \stackrel{\mathrm{CH}_{3}^{+}}{----->} \mathrm{CH}_{3} \mathrm{AsO}(\mathrm{OH})_{2} \stackrel{2 \mathrm{e}^{-}}{--->} \mathrm{CH}_{3} \mathrm{AsO}(\mathrm{OH})^{-} \mathrm{CH}_{3}^{+}---> \\
& 2 \mathrm{e}^{-} \quad \mathrm{CH}_{3}^{+} \quad 2 \mathrm{e}^{-}
\end{aligned}
$$

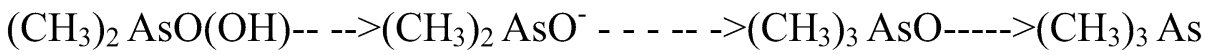

Fig. 1. Proposed mechanism for the methylation of arsenic [8].

of a methyl group from S-adenosylmethionine (SAM) to As in the presence of ATG, then MADG forms a substrate of Cyt 19 for further methylation to dimethylarsinic glutathione (DMAG). These compounds (MADG and DMAG) oxidized to MA and DMA respectively, which are found as major As metabolites in human urine [9].

The methylation process is generally considered to be a detoxification process, because MA and DMA produced from the methylation process are less toxic than inorganic As. However, because other intermediates in the pathway - namely MA(III) and DMA(III) - are now known to be more toxic than inorganic As [10], the detoxification role of the pathway has recently been questioned by Ma and Le [11]. DMA has been reported as a major metabolite after the ingestion of arsenosugars, which are present in seaweed. This has led to the conclusion that consumption of the arsenosugars could pose a risk to human health $[12,13]$. Many studies of As speciation have focused on the separation/quantification of As(III), $\mathrm{As}(\mathrm{V}), \mathrm{MA}, \mathrm{DMA}$ and $\mathrm{AB}$. The separation of these As species is $\mathrm{pH}$ dependent with the following pKa1 values: 9.3, 2.3, 2.6, 6.2 and 2.2 respectively [14] (also see Table 1). A simplified schematic diagram indicating the fate of As in humans, from exposure to excretion (in urine), is shown in Fig. 2. This Figure lists the most commonly found As species in human urine and also shows the main biotransformation steps involved in human As metabolism.

\subsection{Arsenic metabolism as a function of genetics/ethnicity, diet and exposure}

The role of genetics in arsenic metabolism is still at its infancy, and very few studies have been carried out in this field. However, several genes related to As metabolism have been identified, such as the glutathione S-transferase (GST) genes (for example GSTM1 and GSTP1 null genotypes), and are related to higher percentage excretion of MA and DMA respectively [16,17]. In addition, it has been reported in a review by Aposhian and Aposhian [18] that a number of polymorphisms in human GST omega $(\omega)$, CYT 19 and purine nucleoside phosphorylase (PNP) are also linked with changes in urinary As species. Regarding ethnicity, some studies indicate that there is a relationship between As metabolism and ethnicity $[14,19,20]$. However, this has not been unequivocally proven as most of these studies have been performed among exposed population using primarily epidemiological data. Some of these studies compared different population residing in different countries, which introduce a problem related to lack of control for variation issues such as diet [20]. Brima et al. [21] recently reported on the role of ethnicity and As metabolism with population not exposed to As-contaminated water. This study explored differences in levels of total As and As speciation in human urine of three ethnic communities living in one city in the UK. The study revealed that different ethnic groups have significantly different levels of urinary As, both in regards to total As and percentage of DMA. The cause of these differences was not clearly identified and could be due to diet, genetics or a combination of both. Clearly more work needs to be done in the field of genetic/ethnicity and As metabolism with a large group of volunteers with controlled diet and for both exposed and unexposed populations. 


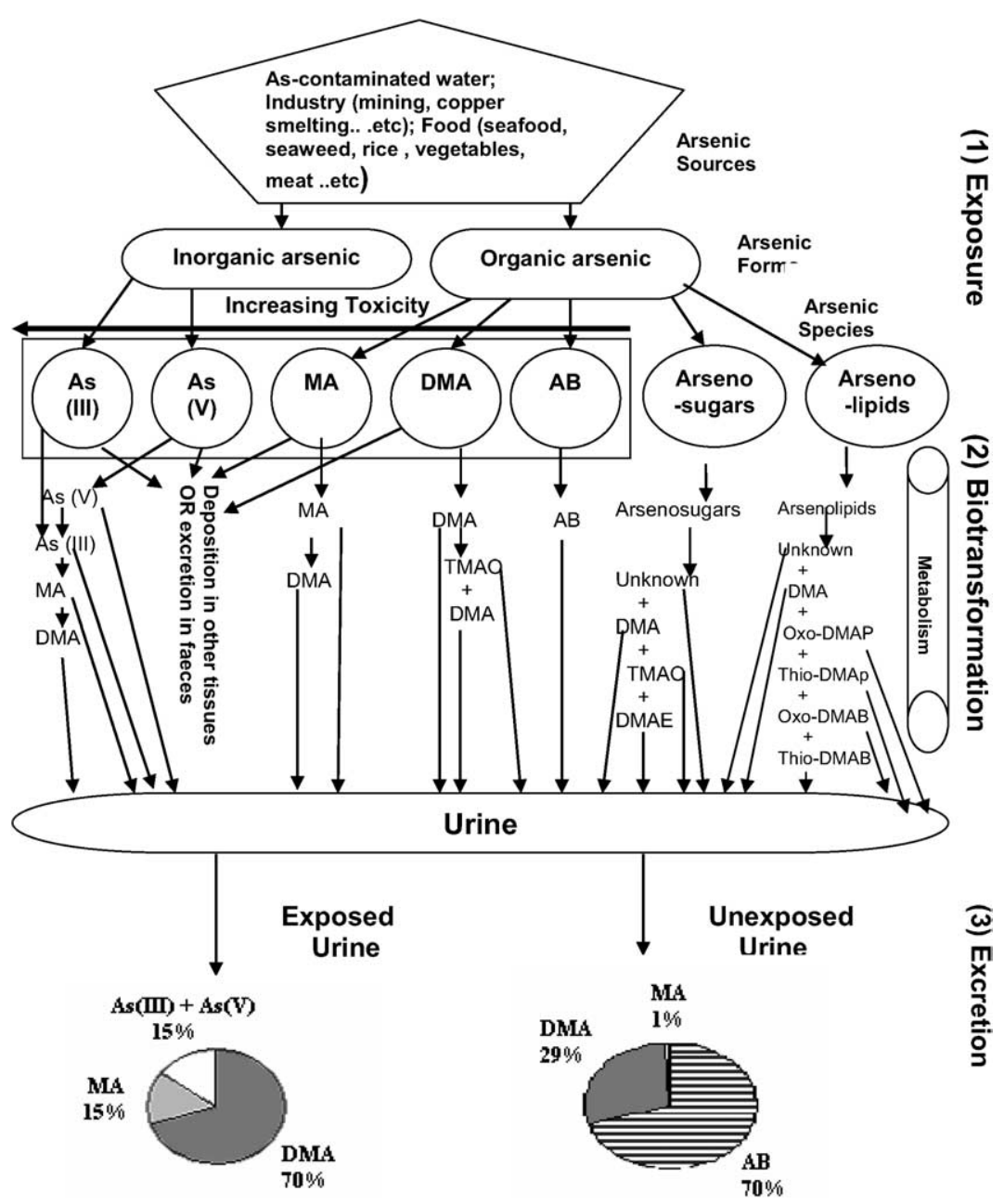

Fig. 2. A simplified flow chart describing the fate of As in humans starting from exposure and ending with excretion of As in human urine for exposed [15,34] and unexposed [21] populations. The Figure illustrates the current understanding of As metabolism in humans based on previous studies reported in the literature. For definition of the abbreviations, see Tables 1 and 3 .

In order to understand As metabolism in humans, ingestion studies have been carried out using food rich in As such as seafood and seaweed. In addition to $\mathrm{AB}$, which is the predominant As species in seafood [22], a substantial increase in DMA was observed in urine, resulting from metabolism of arsenosugars in seaweed and mussels [12,23]. The presence of inorganic As and DMA can arise from food sources since Williams et al. [24] reported significant quantities of these species in rice. Moreover, experimental ingestion studies [20,23] reveal individual intervariability in As metabolism [20]. One of the main problems with such experimental ingestion studies is concern regarding consumption of Asrich food by volunteers. Therefore, often these studies are carried out with small number of volunteers (5-10) making it difficult to attain reliable conclusions. Generally, experimental ingestion studies with toxic As compounds are carried out with animals [25]. However, Buchet and Lauwerys [26] reported an ingestion experiment among 34 volunteers, where $500 \mu \mathrm{g}$ As as inorganic As, MA and DMA were administered as a single oral dose. Their results confirmed that no As species other than inorganic As, 
MA and DMA were present in urine. This was alongside a partial methylation of inorganic As to MA and DMA, and MA to DMA; DMA was excreted unchanged. In another DMA ingestion study in humans (the ingested DMA was equivalent to $0.1 \mathrm{mg}$ As/kg body weight), however, Marafante et al. [27] reported that $4 \%$ of the ingested DMA was excreted as TMAO in urine.

Exposure to As in drinking water is a major area of research. Many studies have been carried out with exposed populations in different countries with high level of As in their drinking water, especially Bangladesh, India, Argentina, Taiwan and Chile [2,28-31]. The mechanism underlying the presence of As in groundwater in West Bengal and Bangladesh is unclear although recent studies suggest metalreducing bacteria may play a role [32,33]. Different As species were reported in the urine of populations exposed to arsenic in drinking water (mainly inorganic As), with percentages of commonly found species being 60-80\% DMA, 10-20\% MA and 10-20\% inorganic As [15,34]. Some studies investigating exposed populations have not adequately controlled the diet of the volunteers, which raises doubts regarding the distribution of As species detected in urine [29]. Inhalation is also considered as a route of exposure to As; in a single case in a laboratory a human inhaled trimethylarsine (TMA) during a synthesis process. The inhaled TMA was believed to be metabolised to AB in the human body [35], because higher level of $\mathrm{AB}$ than the background level was detected in urine after exposure to TMA. This however has been questioned by others [36].

\section{Why analyse urine?}

Urine is widely recognised as an important biofluid for identification of biomarkers that can be used for both understanding biochemical processes and developing diagnostic tests. The vast majority of studies investigating As in humans have focused on determining total As and As species in urine rather than other commonly used biological samples such as blood, hair or nail. This is because the clearance of As from the blood is very rapid [31] and As content of hair and nails is prone to external contamination [37]. Furthermore, analysis of urine sample has the added advantage that it is abundant and easy to collect. Up to $80 \%$ of ingested As is excreted in urine after 3 days [13], making inorganic As in urine sample an important biomarker for determining recent exposure.

\subsection{Measurement of urinary creatinine for normalising As concentration}

Creatinine adjustment is routinely used to reduce some factors that are not related to As level in urine, such as urine concentration and urine volume [38]. The urine volume can be influenced by fluid intake and respiration rate, in order to facilitate urine samples comparison; specific gravity and dry mass were also used for the adjustment [12,39]. It is worth mentioning that creatinine excretion varies with different factors such as gender, age, body mass and intake of cooked meat [38,39]. However, in population studies investigating environmental As exposure, the creatinine adjustment may not be required [38].

\subsection{Urine collection and storage}

Human urine samples are usually collected in polyethylene bottles and stored at 4 or $-20^{\circ} \mathrm{C}$ prior to analysis. Previous studies have suggested that storage conditions have an effect on the stability of As species present in human urine. In stability studies [15,40,41] involving spiking urine with As species, $\mathrm{As}(\mathrm{III}), \mathrm{As}(\mathrm{V}), \mathrm{MA}(\mathrm{V}), \mathrm{DMA}(\mathrm{V})$ and $\mathrm{AB}$ were stable for up to 2 months when stored at $4^{\circ} \mathrm{C}$ or $-20^{\circ} \mathrm{C}$ and for 1 month at $25^{\circ} \mathrm{C}$. The stability of MA(III) and DMA(III) under different conditions have been 
described by Gong et al. [41]. More than $90 \%$ of MA(III) was oxidized to MA(V) within 5 months at $4{ }^{\circ} \mathrm{C}$ and $-20^{\circ} \mathrm{C}$ and completely oxidized to MA(V) within a week at $25^{\circ} \mathrm{C}$, while DMA(III) was completely oxidized to DMA(V) within one day at the previous mentioned conditions $\left(4^{\circ} \mathrm{C}\right.$ and $\left.-20^{\circ} \mathrm{C}\right)$ and 17 hours at $25^{\circ} \mathrm{C}$. Chen et al. [41] investigated the stability of As(III), As(V), MA(V) and DMA(V) species in human urine at $-20^{\circ} \mathrm{C}$ and found their levels constant for up to 6 months. For longer period of storage of up to 8 months, the stability has been shown to be both temperature and urine matrix dependent $[1,15]$. Yoshinaga et al. [42] carried out a study to investigate the stability of AB and DMA in freeze-dried urine (CRM NIES No. 18) over a period of 2 and 1 years respectively by analysing freshly reconstituted samples. The freeze-dried CRM of these species were found to remain stable during storage at $4{ }^{\circ} \mathrm{C}$ [42].

A recent study by Valenzuela et al. [43] found DMA(III) was $49 \%$ and MA(III) was $7.4 \%$ of the total As in urine samples from Mexicans chronically exposed to high As in their drinking water. The analysis was carried out within 6 hours after the collection; the urine samples were frozen in dry ice prior to analysis. These results, however, have been questioned by others [18] who have speculated on the presence and influence of reducing substance in urine in relation to diet.

We carried out an experiment to evaluate the stability of naturally occurring As species in human urine, which was freshly collected from a volunteer. A urine sample was collected from a volunteer who had refrained form eating fish and seafood for 3 days prior to sample collection. The sample was stored at $-20^{\circ} \mathrm{C}$ and then subjected to As speciation over a period of six months. We found that the As species compounds ( $\mathrm{AB}$ and $\mathrm{DMA}$ ) remained constant during this period. The determined values are as follows: $\mathrm{AB}$ prior to storage $(19.25 \pm 0.23 \mu \mathrm{g}$ As/l) and after storage $(19.20 \pm 1.50 \mu \mathrm{g}$ As/l); DMA prior to storage $(4.30 \pm 0.23 \mu \mathrm{g} \mathrm{As} / \mathrm{l})$ and after storage $(4.00 \pm 0.77 \mu \mathrm{g} \mathrm{As} / \mathrm{l})$.

\subsection{Speciation versus total analysis}

Toxicity of As varies with chemical species and chemical speciation is therefore essential in risk assessment [44]. Since biological monitoring requires an accurate analytical method, certified reference material (CRM) is of crucial importance for evaluating method performance. The methods used for the certification of As in human urine have previously been discussed [42]. Total urinary As can not be used as an indicator of exposure to toxic As species because it overestimates exposure for those who have consumed food containing non-toxic As (e.g. seafood rich in AB) [45]. However, determination of toxicologically relevant As compounds (As(III), As(V), MA, DMA) in urine can be used as an indicator of an individual exposed to toxic As. When an individual is exposed to $\mathrm{As}(\mathrm{V})$ it may be reduced to As(III) then methylated to MA and DMA sequentially [46]. It is also increasingly being realised that DMA(III) and MA(III) are more toxic than As(III) and As(V) [40]. Table 1 shows structures, formulae, molecular weights and pKa values for commonly occurring arsenic containing compounds found in food and the environment, that have been also detected in human urine.

\section{Methodology}

Before the urine sample is analysed using spectroscopic techniques it must be subjected to a number of pre-treatment steps. The first step is often filtration, usually through $0.45 \mu \mathrm{m}$ membrane filter. Subsequently the urine is diluted to alleviate the matrix effect. Thereafter, in the case of speciation analysis HPLC is used to separate the different As species. The sample is then subjected to spectroscopic analysis that identifies and quantifies the different species. Table 2 shows the advantages and disadvantages of the different spectroscopic techniques. Table 3 gives selected references that describe these techniques, 


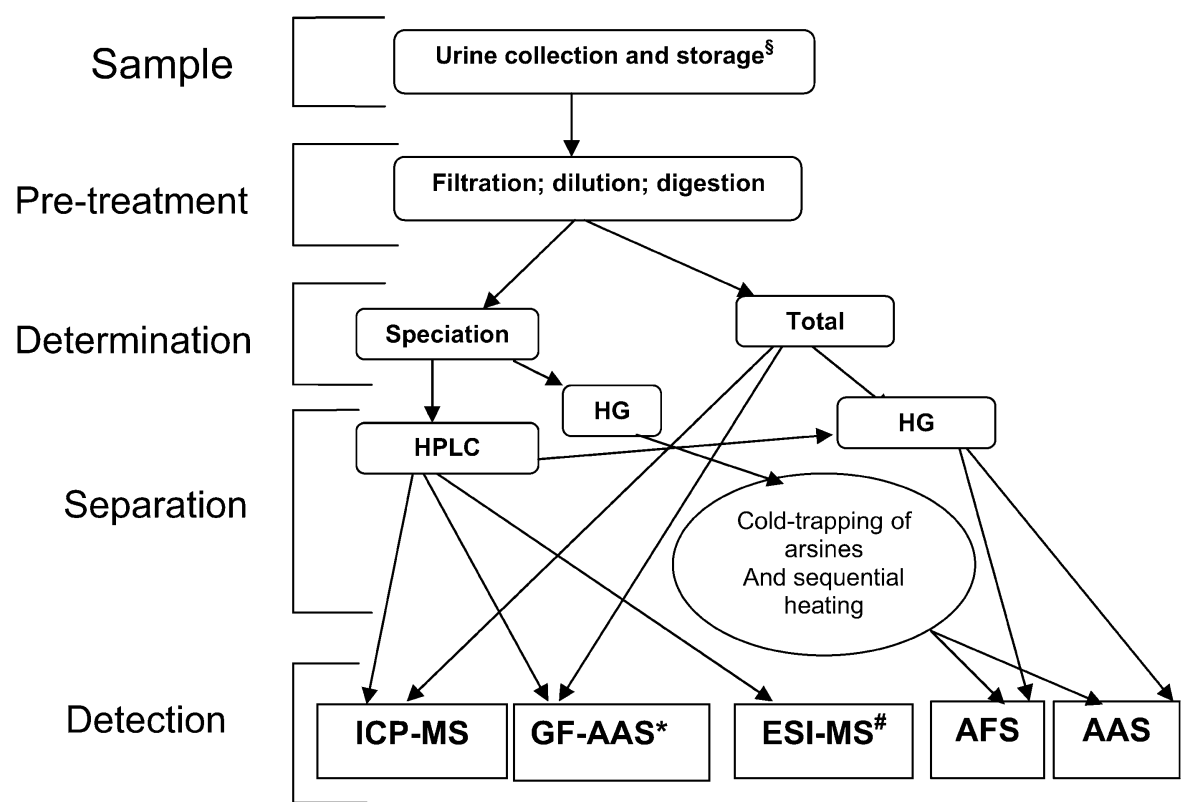

Fig. 3. Schematic diagram showing steps involved in urine analysis using different spectroscopic techniques. HPLC: High performance liquid chromatography; ICP-MS: Inductively coupled plasma - mass spectrometry. HG-AAS: Hydride generation atomic absorption spectrometry; HG-AFS: Hydride generation atomic fluorescence spectrometry; ESI-MS: Electrospray ionisation mass spectrometry; GF-AAS: Graphite furnace - atomic absorption spectrometry. ${ }^{\S}$ Polyethylene bottles are generally used for urine collection, and stored at 4 or $-20^{\circ} \mathrm{C}$ prior to analysis. " Off-line speciation. ${ }^{\#}$ Speciation only.

Table 2

Advantages and disadvantages of different spectroscopic techniques that are used for arsenic measurement in human urine

\begin{tabular}{|c|c|c|}
\hline Technique & Advantages & Disadvantages \\
\hline ICP-MS & $\begin{array}{l}\text { - Sensitive } \\
\text { - Low limit of detection } \\
\text { - Large dynamic range } \\
\text { - Multi-element detection }\end{array}$ & $\begin{array}{l}\text { - Expensive } \\
\text { - Polyatomic interference }\end{array}$ \\
\hline HG-AAS & $\begin{array}{l}\text { - Sensitive } \\
\text { - Low limit of detection } \\
\text { - Relatively free of interference } \\
\text { - Selective } \\
\text { - Simple }\end{array}$ & $\begin{array}{l}\text { - Detects only hydride generated arsenic com- } \\
\text { pounds (As(III), As(V), MA, DMA). There- } \\
\text { fore, can not detect certain organoarsenic } \\
\text { compounds, e.g. AB, AC, and } \mathrm{Me}_{4} \text { As. } \\
\text { - HG is pH dependent. }\end{array}$ \\
\hline HG-AFS & $\begin{array}{l}\text { - Low limit of detection than HG-AAS } \\
\text { - Relatively free of interference } \\
\text { - Selective } \\
\text { - Simple } \\
\text { - Few memory effect } \\
\text { - Decreased background signal } \\
\text { - Wide linear range }\end{array}$ & $\begin{array}{l}\text { - Detects only hydride generated arsenic com- } \\
\text { pounds (As(III), As(V), MA, DMA). There- } \\
\text { fore, unresponsive to certain organoarsenic } \\
\text { compounds, e.g. AB, AC and } \mathrm{Me}_{4} \text { As. } \\
\text { - HG is pH dependent. }\end{array}$ \\
\hline GF-AAS & $\begin{array}{l}\text { - Simple } \\
\text { - Little sample preparation is required }\end{array}$ & $\begin{array}{l}\text { - Mostly total arsenic } \\
\text { - Speciation can only be performed off-line }\end{array}$ \\
\hline LC-MS & - Structure confirmation & $\begin{array}{l}\text { - High limit of detection } \\
\text { - Affected by the sample matrix }\end{array}$ \\
\hline
\end{tabular}


Table 3

Studies in which arsenic metabolites in human urine have been analysed using different spectroscopic techniques. The Table is not intended as a comprehensive summary of all the studies reported in the literature, but gives examples of selected applications

\begin{tabular}{llc}
\hline Detection & Species identified & Ref. \\
\hline ICP-MS & Total arsenic & {$[47]$} \\
ICP-MS & As(V), As(III), DMA, MA & {$[48]$} \\
ICP-MS & As(V), As(III), DMA, MA, AB & {$[14]$} \\
ICP-MS & AB, AC, TMAO, Me 4 As & {$[7]$} \\
ICP-MS & As(V), As(III), DMA, MA, AB, AC & {$[49]$} \\
ICP-MS & As(V), As(III), DMA, MA, AB, AC, Me 4 As ${ }^{+}$ & {$[50]$} \\
ICP-MS & DMA, TMAO, Oxo-DMAE, Thio-DMAE, Oxo-DMAA, & {$[51]$} \\
& Thio-DMAA, Thio-arsenosugar & {$[13]$} \\
ICP-MS & DMA, TMAO, DMAE, (9 unknown) arsenosugar metabolites \\
ICP-MS & Diphenylarsinic acid & {$[52]$} \\
ICP-MS & DMA, Oxo-dimethylarsenopropanoic acid (Oxo-DMAP), \\
& Thio-dimethylarsenopropanoic acid (Thio-DMAP), & {$[53]$} \\
& Oxo-dimethylarsenobutanoic acid (Oxo-DMAB), & \\
& Thio-dimethylarsenobutanoic acid (Thio-DMAB) & {$[54]$} \\
HG-AAS & Total arsenic & {$[55]$} \\
HG-AAS & As(V), As(III), DMA, MA & {$[49]$} \\
HG-AAS & As(V), As(III), DMA, MA, AB, AC \\
HG-AAS & As(V), As(III), DMA, MA, AB, AC, Me ${ }_{4}$ As ${ }^{+}$ & {$[50]$} \\
HG-AFS & Total arsenic & {$[56]$} \\
HG-AFS & As(V), As(III), DMA, MA \\
HG-AFS & As(V), As(III), DMA, MA, AB, AC, Me 4 As ${ }^{+}$ & {$[55]$} \\
GF-AAS & Total arsenic & {$[50]$} \\
LC-MS & AB, DMA & {$[57]$} \\
\hline
\end{tabular}

and which have been used for total As and As speciation studies. The steps involved in urine analysis starting from the collection step and ending with its analysis using different spectroscopic techniques are summarised in Fig. 3.

\subsection{Inductively coupled plasma - mass spectrometry (ICP-MS)}

\subsubsection{Basic theory}

ICP-MS is considered the most efficient technique for elemental analysis of liquid samples, because of the ease of coupling the instrument to HPLC. A combination of HPLC with ICP-MS is often the technique of choice in As speciation in human urine, because of the resolving power of HPLC and the sensitivity, lower detection limit and large dynamic range of ICP-MS [15].

ICP-MS offers better detection limits for many elements compared to some other spectroscopic techniques, making it a powerful tool for elemental analysis [64]. However, the polyatomic interference produced from the chloride ion present in urine is a major drawback of this technique. Chloride ions react with the argon plasma gas to form argon chloride that has the same molecular weight (75) as arsenic. Three approaches have been used to minimise or eliminate the ${ }^{40} \mathrm{Ar}{ }^{35} \mathrm{Cl}$ interference with As. One has been the use of hydride generation or chromatography to separate the chloride from the As [59]. 


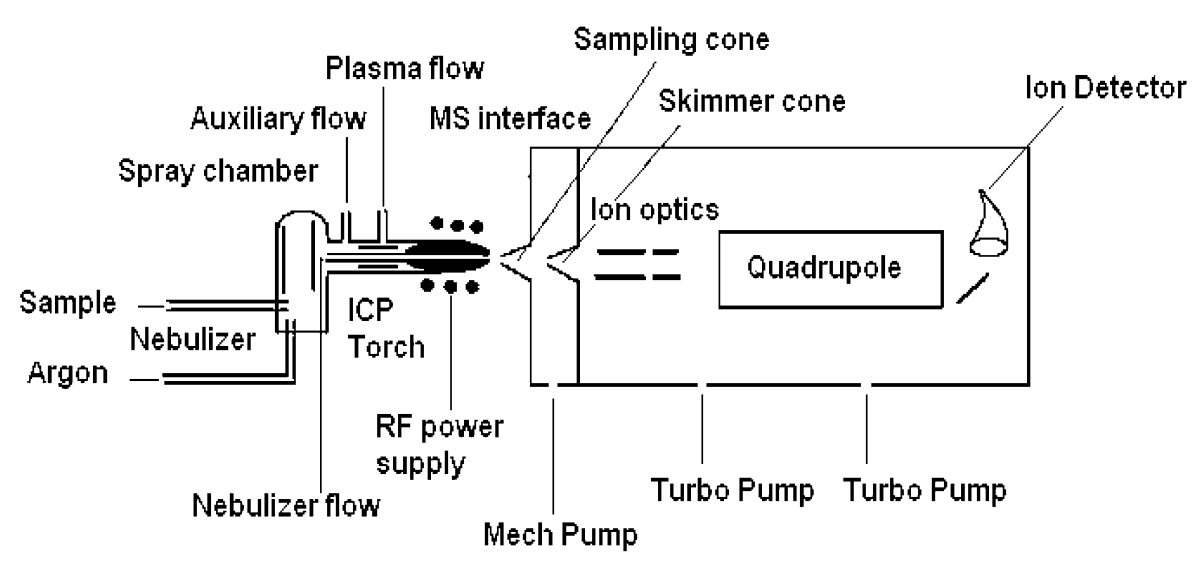

Fig. 4. Schematic diagram describing the typical set-up of ICP-MS instrument.

A second approach has been addition of a molecular gas, such as nitrogen, to the plasma to reduce the formation of ${ }^{40} \mathrm{Ar}^{35} \mathrm{Cl} .{ }^{59}$ The third approach is isotopic correction using either empirically derived relationship of a measured isotope such as ${ }^{16} \mathrm{O}^{35} \mathrm{Cl}$ with ${ }^{40} \mathrm{Ar}{ }^{35} \mathrm{Cl}$ or using the classical ${ }^{40} \mathrm{Ar}^{37} \mathrm{Cl} /{ }^{82} \mathrm{Se} /{ }^{83} \mathrm{Kr}$ correction based on known isotope abundances [7]. The mathematical correction for ${ }^{40} \mathrm{Ar}{ }^{35} \mathrm{Cl}$ is as follows [59]:

$$
I\left({ }^{75} \mathrm{As}\right)=I\left({ }^{75} \mathrm{As}\right)-R\left({ }^{35} \mathrm{Cl} /{ }^{37} \mathrm{Cl}\right) \times\left\{I(77)-R\left({ }^{77} \mathrm{Se} /{ }^{82} \mathrm{Se}\right) \times\left[I(82)-R\left({ }^{82} \mathrm{Kr} /{ }^{83} \mathrm{Kr}\right)\right]\right\},
$$

where $I$ is the intensity and $R$ is the ratio of natural abundances of specified isotopes.

Two other approaches can also be used to remove the polyatomic interferences. One approach involves using a high resolution mass spectrometer (sector field double focusing) instead of a quadrupole analyzer. Another approach offers two possibilities for chemical resolution of interferences: (1) by collision/reaction of the interfering polyatomic ions with gases such as $\mathrm{H}_{2}, \mathrm{He}$ or Xe, which destroy a polyatomic ion and consequently remove it from the $m / z$ range of interest; and (2) by reaction of the ion of interest with oxygen, which results in the formation of a new product ion that can be detected at a new non-interfered $m / z$ value [60]. The above-mentioned approached to overcome the polyatomic interferences - chromatography, reaction/collision cell technology, high resolution mass analyser, mathematical correction - have been reported in recent reviews [61-63].

A schematic representation of an ICP-MS is shown in Fig. 4. In ICP-MS the sample is converted into an aerosol by a nebulizer. Large droplets that may be produced by the nebulizer must be removed in the spray chamber, in order to increase the precision and to decrease interferences. The aerosol is subsequently transported into the plasma, which usually operates at temperatures of 5000-10000 K at atmospheric pressure. Therefore the ICP is a high energy and hard ionization source, where the following processes occur sequentially and nearly simultaneously: desolvation-vaporization-atomizationexcitation-ionization of the analyte [61,64]. In the ICP-MS the end tip of the plasma is extracted into a low-pressure interface containing both a sampler and skimmer cone. The plasma formation takes place in a stream of argon gas flows through an assembly of three concentric quartz tube known as a plasma torch, as shown in Fig. 4. The torch is surrounded at the top by an induction coil connected to a radiofrequency (RF) generator. The induction coil is made of copper and cooled by argon gas or water. A current in argon gas is induced by a magnetic field generated by the RF through the coil, after the argon gas is seeded with energetic electrons. These electrons are produced either by a high voltage, or a solid state 
piezoelectric transducer. An efficient introduction of sample aerosol into a central channel of the plasma results in the efficient desolvation, vaporization, atomization, excitation, and ionization of the sample. A simultaneous multi-element determination can be carried out by the argon ICP, since ICP is capable of exciting-ionizing a wide range of elements, especially metals. The argon plasma gas isolates and confines an analyte passageway, which results in sequestering of the analyte's atomic and ionic species that provides optimum conditions for its sampling from the ICP. The sampling cone orifice of the ICP-MS interface (Fig. 4) can be easily positioned along the axial channel in a region that leads to maximum analyte signal and minimum background intensity for mass spectrometric measurements. A number of voltages must be set with respect to the ion optics of the mass spectrometer, which in turns depends on type of ion optics used. As the transmission is mass dependent, it is likely to program the voltage of an ion lens (Fig. 4) in accordance with the quadruple scan. Therefore the optimal lens voltage is applied as a function of mass. A quadruple-based mass analyzer is used in an ICP-MS instrument because of its relative simplicity, low cost, and good performance [64]. Further details regarding the background theory of ICP-MS may be obtained from a recently published book [64].

The main advantage of ICP-MS is that it has a very low detection limit for As. It also provides a large dynamic range, which enables the detection of As in urine samples over a wide range of concentrations. In addition its multi-element detection capability allows detect simultaneously determination of different elements in samples. More advantages and disadvantages related to ICP-MS instruments and uses of collision cells and reaction cells are reviewed in details by Tanner et al. [65]. The major disadvantage of ICP-MS is polyatomic interferences, although as already mentioned various procedures can be used to overcome this problem. In addition, ICP-MS has the added disadvantage of being a relatively expensive instrument to purchase.

\subsubsection{Application of ICP-MS for urine analysis}

It is beyond the scope of this review to discuss all the different type of studies performed using ICPMS. We have therefore selected some recent examples of application of ICP-MS for analysis of urine samples in relation to ethnicity, experimental ingestion studies, and exposure studies.

\section{(i) Relationship between arsenic metabolism and genetics/ethnicity}

Ethnicity and race have been defined as follows: an ethnic group can be defined as "a large groups of people classed according to common racial, national, tribal, religious, linguistic, or cultural origin or background" and race is "a family, tribe, people, or nation belonging to the same stock or a class or kind of people unified by community of interests, habits, or characteristics" [66]. As reported by Margaret et al. [67] "The Human Genome Project has found that the human population has $99.9 \%$ of its DNA in common" according to a reference cited therein [68].

Very little is known about the relationship between genetic/ethnicity and As metabolism. We have recently carried out a study investigating urinary arsenic in three ethnic groups (Somali, Asian and White) living in the same city in the UK. This study was carried out to explore if there are differences in As levels and As species between these groups. The study was conducted using ICP-MS for total As in urine samples, which was done after a filtration of sample using a $0.45 \mu \mathrm{m}$ syringe filter, with subsequent dilution 5-fold with $2 \% \mathrm{v} / \mathrm{v} \mathrm{HNO}_{3}$. Yttrium was used as internal standard. For speciation analysis HPLC was coupled with ICP-MS, the samples were filtered as above and diluted 5-fold with the mobile phase (20 $\mathrm{mM} \mathrm{NH}_{4} \mathrm{HCO}_{3}, 5 \% \mathrm{CH}_{3} \mathrm{OH}$ and $\mathrm{pH}=10.3$ ). The column used in speciation analysis was a PEEK Hamilton PRP-X 100 anion exchange column $(250 \times 4.1 \mathrm{~mm}$ i.d. $)$ with a guard column: Phenomenex Polymerx RP-1 (4 $\times 3 \mathrm{~mm}$ i.d.), $\mathrm{pH}$ stability (1-14). Germanium was used as internal standard. The arsenic species analysed were AB, DMA, As(III), MA and As(V). This study revealed that there was 
a significant difference among the ethnic groups regarding total arsenic and arsenic species in human urine. The results obtained clearly show that the total level of arsenic in urine samples of Somali BlackAfricans ( $7.2 \mu \mathrm{g} / \mathrm{g}$ creatinine) is significantly different from the Asians ( $20.6 \mu \mathrm{g} / \mathrm{g}$ creatinine) and Whites (24.5 $\mu \mathrm{g} / \mathrm{g}$ creatinine). Furthermore, the proportion of total urinary arsenic as DMA for Somali BlackAfricans (50\%) is higher than Asians (16\%) and whites (22\%). This suggests an unusual pattern of arsenic metabolism in Somali group, likely to be due to a combination of dietary and genetic differences, which need to be further, investigated [21].

The relationship between genetics and As metabolism has been rarely investigated. However, there are few studies have indicated that arsenic metabolism is modulated by genetic polymorphism. Here we give an example of a study that involved analysis of urinary As related to genetic (CYT19) polymorphism. Urine samples of 135 volunteers from Mexico, exposed to drinking water with arsenic concentration (5.5-43.3 $\mu \mathrm{g} / \mathrm{l})$, was studied by Meza et al. [69]. Total As in urine samples was analysed by using ICP-MS after a digestion process with nitric acid using a microwave oven following a protocol by Francesconi et al. [70]. For speciation analysis frozen urine samples were thawed at room temperature, diluted (2-fold) with Milli-Q water and filtered with $0.45 \mu \mathrm{m}$ filter before injection into HPLC. The speciation analysis was carried out by using ICP-MS as a detector for analysis of arsenic species: As(III), As(V), DMA and MA with the following chromatographic conditions (isocratic): reverse-phase column C18 (ODS, $150 \times 4.6$ i.d. mm; Phenomenex, Torrance, CA, USA). This study revealed a strong association among arsenic-exposed population between polymorphisms of CYT19 and DMA : MA ratio in Mexican children. However, no significant similar association was observed among the Mexican adults [69].

\section{(ii) Understanding arsenic metabolism through experimental ingestion studies}

In order to investigate the relationship between diet and As metabolism some workers have monitored As levels in volunteers who were asked to ingest specific types of food. This includes studies where volunteers were asked to consume seafood [20], seaweed [13,71,72] and pure arsenosugar [51]. These studies focused on understanding the urinary excretion pattern of As metabolites subjected to ingestion of seafood by humans. In a seafood ingestion study, Lai and co-workers [20] used HPLCICP-MS to investigate metabolism of As in humans through speciation analysis of urine after seafood (mussels) consumption by nine volunteers. The following chromatographic conditions (isocratic) were used: reverse-phase C18 column (GL Sciences Intersil ODS, $250 \times 4.6 \mathrm{~mm}$ ) and C18 guard column (Supelco, $2 \mathrm{~cm}$ ); the mobile phase was $10 \mathrm{mM}$ tetraethylammonium hydroxide, $4.5 \mathrm{mM}$ malonic acid, $0.1 \%$ methanol, pH 6.8. They showed that As excretion for the nine volunteers was similar, with the exception of one volunteer who was known to be a frequent seafood eater. The major metabolites after the seafood ingestion were found to be AB, DMA and significant amounts of unidentified metabolites. In another experimental ingestion study, Matsuura and co-workers [71] investigated urinary arsenic excretion pattern after one-time ingestion of seaweed [hijiki (Hizikia fusiforme)]. The authors found that the urinary excretion pattern for inorganic As and methylated As compounds were different. The highest concentrations of inorganic arsenic $\mathrm{As}(\mathrm{V})$ and $\mathrm{As}(\mathrm{III})$ were observed 10 hours after ingestion. In contrast, organoarsenic compounds (AB, DMA and MA) were observed 21 hours after ingestion of the seaweed. The finding of this experiment suggested that the human body is capable of performing a detoxification process by rapid excretion of toxic inorganic arsenic through a methylation process.

Hulle et al. [13] carried out an experimental ingestion study aimed at investigating metabolism of arsenosugars and identify its As containing urinary metabolites. The experiment was carried out with five volunteers who were asked to ingest seaweed (Laminaria). HPLC-ICP-MS was used for speciation 
analysis. The chromatographic conditions (isocratic) used were as follows: anion exchange column PRPX100 (Hamilton, Reno, NV, USA, $250 \times 4.1 \mathrm{~mm}$ ) with a mobile phase $20 \mathrm{mM} \mathrm{NH}_{4} \mathrm{HPO}_{4}$ in $3 \%$ methanol at $\mathrm{pH} 7$; different ammonium mobile phases were also used with a $\mathrm{pH}$ range from 6-6.5 and methanol range from 2-20\%; cation exchange column (Dionex, Sunnyvale, CA, USA, $250 \times 4 \mathrm{~mm}$ ) with a mobile phase of $20 \mathrm{mM}$ pyridine at $\mathrm{pH}$ 2.7. The authors detected DMA, MA, dimethylarsinoylethanol (DMAE) and five unknown As species in human urine as arsenosugars metabolites after the ingestion of the seaweed.

Raml et al. [51] investigated the effect on human health associated with the ingestion and metabolism of arsenosugars in an ingestion experiment where one volunteer was asked to ingest a pure arsenosugar (oxo-arsenosugar, containing $945 \mu \mathrm{g}$ of As). The volunteer refrained from eating food known to contain significant concentrations of arsenic such as seafood and mushrooms for 3 days before and during the experiment. In this study, ICP-MS was used for total arsenic in urine after a digestion process with nitric acid. The speciation analysis was carried out by using HPLC in combination with ICP-MS. Five different chromatographic conditions (isocratic) were employed for speciation analysis by using different columns and elution buffers: anion exchange (PRP-X100), cation exchange (Zorbax 300 SCX and Ionospher) and reverse column C18 (Atlantis); pyridine and buffers of carbonate and phosphate over a $\mathrm{pH}$ range of 2.6-9.0. The authors identified novel thioarsenic metabolites and a cytotoxicity test confirmed that these metabolites were not toxic. The new metabolites were thio-arsenosugar, thiodimethylarsinoylethanol (thio-DMAE), thio-dimethlyarsinoylacetate (thio-DMAA), and oxo-dimethylarsinoylacetate (oxo-DMAA).

Recently Francesconi and co-workers [53] investigated the metabolism of arsenic-containing lipids in humans by monitoring the urine samples of two male volunteers after ingestion of canned cod liver and pure cod-liver oil. The arsenic containing metabolites in their urine samples were monitored using HPLC-ICP-MS. The authors carried out the analysis over a 66-h period. ICP-MS was used for total arsenic in urine after a digestion process with microwave-assisted acid (nitric) digestion. The speciation analysis was carried out under anion- and cation-exchange conditions by using HPLC in combination with ICP-MS. The anion exchange (PRP-X100), cation exchange (Zorbax 300 SCX) and reverse-phase chromatography used was previously reported by Schmeisser et al. [73]. For anion-exchange chromatography the following mobile phases were used at $4{ }^{\circ} \mathrm{C}: 20 \mathrm{mmol} \mathrm{dm}{ }^{-3} \mathrm{NH}_{4} \mathrm{H}_{2} \mathrm{PO}_{4}$ at $\mathrm{pH} 5.6$ (adjusted with $25 \%$ aqueous $\mathrm{NH}_{3}$ ), or $20 \mathrm{mmol} \mathrm{dm}{ }^{-3} \mathrm{NH}_{4} \mathrm{HCO}_{3}$ with $3 \% \mathrm{MeOH}$ at $\mathrm{pH} 10.3$ (adjusted with aqueous $\mathrm{NH}_{3}$ ). For cation-exchange chromatography the following mobile phases were used at $30^{\circ} \mathrm{C}$ : $20 \mathrm{mmol} \mathrm{dm}{ }^{-3}$ aqueous pyridine solution at a pH 2.6 (adjusted with formic acid). Cod liver contains a mixture of arsenolipids and arsenobetaine. The authors found that after ingestion of cod liver, the arsenolipids were rapidly metabolised to water soluble compounds and excreted in the urine. The major species excreted was DMA for both volunteers. Four novel arsenic-containing fatty acids, namely thio-dimethylarsenopropanoic acid (Thio-DMAP), oxo-dimethylarsenopropanoic acid (Oxo-DMAP), thio-dimethylarsenobutanoic acid (Thio-DMAB) and oxo-dimethylarsenobutanoic acid (Oxo-DMAB) constituted the remaining arsenolipid-derived arsenic. Unaltered arsenobetaine, which constitutes the majority of the non-lipid arsenic in cod liver, made up the remaining urinary arsenic together with trace quantities of mostly unknown arsenic species. In their experiment with pure cod liver oil, which is reported to contain only arsenolipids, the urine samples of the volunteers contained DMA and the same four arsenic fatty acids that were found after ingestion of cod liver [53].

(iii) Arsenic metabolism in exposed groups - Exposure through diet and environment

Metabolism of As in relation to exposure to inorganic As through consumption of environmentally contaminated drinking water is by far the most widely studied topic in this area. This is because of natural 
contamination of ground water by As in different parts of the world, including India and Bangladesh [74]. The majority of the studies were conducted using ICP-MS for both total As and As species in human urine. The purpose of these studies was either to use inorganic As, MA and DMA as a biomarker of exposure or to gain a better understanding of As metabolism in the human body. Unfortunately, since data on non-exposed populations are limited, comparative analysis of As metabolism in exposed and unexposed populations is not easy.

The As species in human urine of people living in an As-affected area of India (Murshidabad district, West Bengal) were investigated by Tokunaga et al. [2] in order to obtain information about the correlation between As species in urine and As levels in tube-well water used as drinking water. HPLC in combination with ICP-MS was used for As speciation in urine samples. The chromatographic conditions (isocratic) were as follows: The analytical column was cation exchange Gel PAK GL-IC-A15 $(150 \times 4.6 \mathrm{~mm})$; the mobile phase was $10 \mathrm{mM}$ phosphate buffer $(\mathrm{pH} \mathrm{6.0)}$. Total As in drinking water was found to be in the range of 2.7-170 $\mu \mathrm{g} / \mathrm{l}$ and the average total arsenic in urine was $59.2 \mu \mathrm{g} / \mathrm{l}$ (mg creatinine/ml urine), after an investigation of 51 urine samples. The major arsenic species in urine were DMA and MA, which represented $83 \%$ of the total As in urine. A positive correlation was observed from this study between As concentration in tube well water and As(III), MA, DMA and total As in urine [2].

Chowdhury et al. [29] studied the pattern of excretion of arsenic compounds (As(III), As(V), MA, DMA) in urine of an exposed population among children and adults from Madaripur district in Bangladesh. Urine samples were collected from 42 volunteers: 24 adults (age range 13-70) and 18 children (age range 3-11). HG-AAS was used for total arsenic analysis and HPLC-ICP-MS was used for speciation analysis, with the following chromatographic conditions (isocratic): cation exchange column Gel PAK GL-A15 $(150 \times 4.6 \mathrm{~mm})$ with a mobile phase of $10 \mathrm{mM}$ phosphate buffer containing $0.2 \mathrm{mM}$ EDTA ( $\mathrm{pH} \mathrm{6}$ ). The average total As in water, adult urine and children urine were $376 \mu \mathrm{g} / \mathrm{l}$, $483.4 \mu \mathrm{g} / \mathrm{l}$ and $606.1 \mu \mathrm{g} / \mathrm{l}$, respectively. Since the value of DMA/MA ratio was significantly higher in children (8.2) than adults (4.1), the authors took this to indicate that the second methylation capacity in children is higher than that of adults. They concluded that this may explain the absence of skin lesions in children compared to adults, when both groups were exposed to the same As contaminated water [28].

Over 100 millions people living in arsenic-affected area are exposed to As in drinking water in West Bengal, India and Bangladesh [2]. This is due to natural contamination from the geology of the groundwater aquifer. There are other parts of the world where As contamination results from human activity such as coal burning, particularly in China [75]. Shraim et al. [76] reported a study aimed at investigating the extent of human exposure to As via coal-burning among the population of Guizhou, China. Urine samples were collected from 38 volunteers and analysed using HPLC-ICP-MS. Speciation analysis was also carried out on the urine samples by using a C18 reversed-phase column (Intersil ODS-3, $150 \times 3 \mathrm{~mm}$ ). Total As in coal, water and urine were $56.3 \mathrm{mg} \mathrm{As} / \mathrm{kg}, 2.3 \mu \mathrm{g} / \mathrm{l}$ and $71.4 \mu \mathrm{g} \mathrm{As} / \mathrm{g}$ creatinine, respectively. The authors revealed that there was a significant difference between females and males in their urinary As levels. Higher DMA and lower percentages of inorganic As were reported in female urine than males [76]. It was suggested that this may be due to high methylation capacity of females compared to males.

In another study, the levels of urinary As in pregnant women from Antofagasta, Chile, was related to selenium (Se) among those exposed to As in their drinking water $(40 \mu \mathrm{g} / \mathrm{l})$. Urine samples were collected from 93 pregnant women and was analysed by using ICP-MS for Se and As. Total As and Se in urine samples were found to be 55.8 and $28.3 \mu \mathrm{g} / \mathrm{l}$, respectively. They found that urinary Se levels were correlated with urinary As levels. Furthermore, higher urinary Se levels were associated with increased urinary As excretion and increased proportion of total As as DMA. The authors concluded that Se 
intake in populations exposed to arsenic is correlated with urinary As excretion and could influence As methylation [77].

To explore the relationship between folate, cobalamin, and homocysteine and As metabolism among exposed adults, total As and As speciation analysis was carried out in human urine of 300 volunteers from Bangladesh [78]. A HPLC-ICP-MS method, which was previously described by Vela et al. [79], was used for speciation. Total As was measured by GF-AAS using a method previously described by Nixon et al. [80]. The authors concluded that folate and homocysteine and other factors influence As methylation. This conclusion was derived from the fact that MA percentage was negatively associated with folate and positively with homocysteine. Inorganic As was negatively associated with folate. In contrast, the percentage of DMA was positively correlated with plasma folate [78].

\subsection{Hydride generation $(H G)$ coupled with atomic absorption spectrometry (AAS) or atomic fluorescence spectrometry (AFS)}

\subsubsection{Basic theory}

Hydride generation (HG) involves a reaction between acidified sample solution with a reducing reagent (tetrahydroborate, $\mathrm{NaBH}_{4}$ ) to generate gaseous hydride; arsine in the case of As analysis. A stream of argon is used to sweep out the hydride and excess hydrogen into a hydrogen diffusion flame. The hydride is then carried by a flow of carrier gas to a heated quartz furnace for atomisation by thermal decomposition. The resulting atoms are detected by atomic fluorescence spectrometry (AFS) [81] or atomic absorption spectrometry (AAS) [82]. A schematic representation of the apparatus is shown in Fig. 5. The principle of HG is as follows [83]:

$$
\mathrm{NaBH}_{4}+3 \mathrm{H}_{2} \mathrm{O}+\mathrm{HCl} \longrightarrow \mathrm{H}_{3} \mathrm{BO}_{3}+\mathrm{NaCl}+8 \mathrm{H} \stackrel{\mathrm{E}^{m+}}{\longrightarrow} \mathrm{EH}_{n}+\mathrm{H}_{2} \text { (excess), }
$$

where "E" is the analyte element and " $m$ " may or may not be equal to " $n$ ".

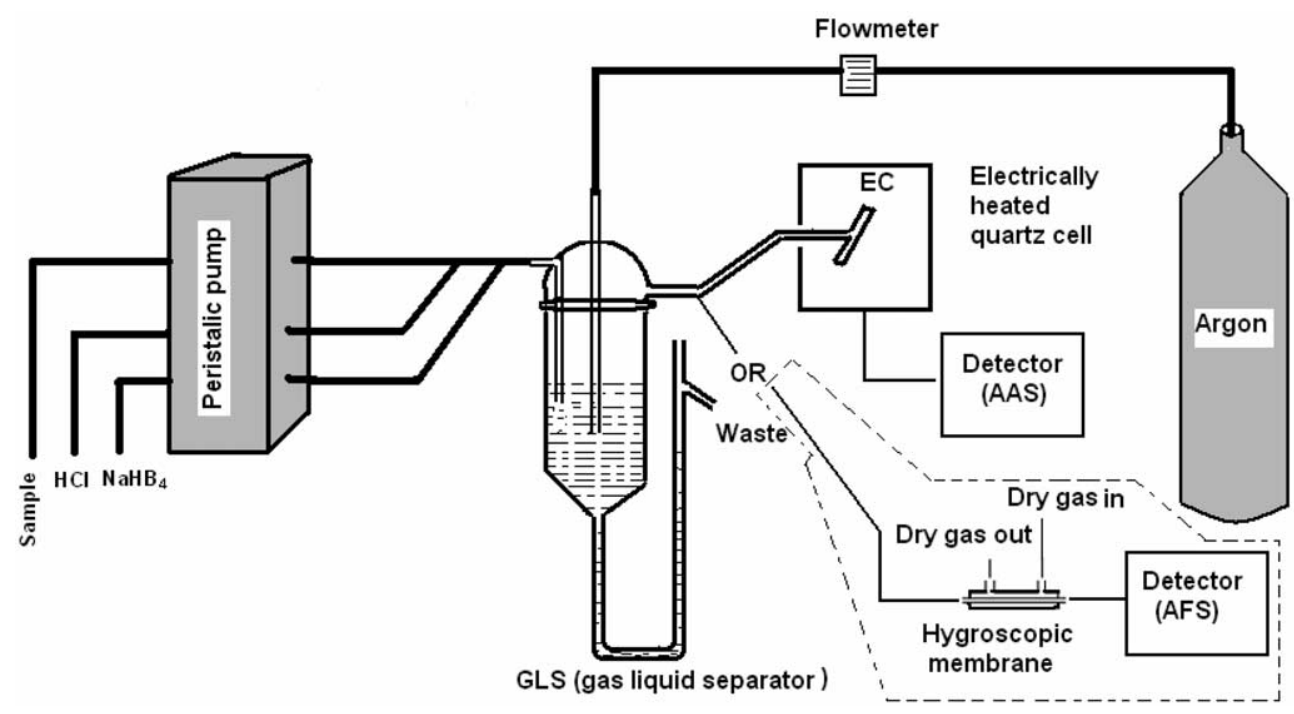

Fig. 5. Schematic diagram describing the typical set-up of a HG-AAS or HG-AFS instrument, with a gas liquid separator (GLS) connected either to an AAS or AFS detector. 
There are two operation modes of a HG system: (i) batch mode and (ii) continuous mode for sample introduction. In the batch mode, the acidified sample and $\mathrm{NaBH}_{4}$ are reacted in a vessel then the hydride carried by a stream of carrier gas directly into a detector; or sometimes the hydride is collected in a trap before being introduced into a detector. In the batch method inorganic As (As(III) and As(V)), MA and DMA are converted to corresponding arsines (arsine, methylarsine and dimethylarsine, respectively), by reaction with $\mathrm{NaBH}_{4}$. The arsines are collected in a cryogenic trap until all arsenic species forming arsines in the sample has reacted, then the cryotrap is warmed and the collected arsine are separated on the basis of differential volatilization [31]. In the continuous mode the acidified sample and $\mathrm{NaBH}_{4}$ are continuously delivered for the production of hydride. Therefore, the hydride of the sample is constantly generated then separated from the liquid waste with a gas-liquid separator and introduced into the detector. In continuous mode a better precision is generally achieved as a result of steady state signal [82,84].

Interferences from transition metals is a limitation to the hydride generation technique. However, interferences may be minimised either by increasing the hydrochloric acid in the final sample solution and reducing the $\mathrm{NaBH}_{4}$ concentration [85], or by adding $1 \%$ cysteine in the sample solution during the analysis of arsenic [82].

It is generally accepted that the following As species: As(III), As(V), MA and DMA and TMAO, and recently arsenosugars compounds in marine organisms were also added to react with $\mathrm{NaBH}_{4}$ to form hydrides [86], while naturally occurring organoarsenic compounds (e.g. AB and AC) do not. Therefore, the latter group of compounds requires decomposition by some means - microwave, $\mathrm{HNO}_{3} / \mathrm{HClO}_{4}, \mathrm{UV}$ photo-oxidation and $\mathrm{K}_{2} \mathrm{~S}_{2} \mathrm{O}_{8}$ - prior to generation of volatile hydride [87-89].

Various arsines are formed from reaction of As species with $\mathrm{NaBH}_{4}$ at a given $\mathrm{pH}$ : $\mathrm{As}(\mathrm{III})$ and $\mathrm{As}(\mathrm{V})$ forms $\mathrm{AsH}_{3}$; MA forms $\mathrm{CH}_{3} \mathrm{AsH}_{2}$; and DMA forms $\mathrm{CH}_{3} \mathrm{AsH}_{2}$. The efficiency of $\mathrm{HG}$ of As species is dependent upon $\mathrm{pH}$, and the efficiency of $\mathrm{HG}$ varies with As species at any given $\mathrm{pH}$. For example, $\mathrm{As}(\mathrm{V})$ gives a significantly lower response than $\mathrm{As}(\mathrm{IIII})$ and it is essential to convert all As species to the As(III) state prior to hydride generation [90]. Thus in samples where the proportions of As species often differ - such as in urine - an error will arise when using HG for determination of total As in urine samples. This error can however be eliminated by the addition of $2 \%$ cysteine to samples prior to hydride generation [6]. These authors proposed that the effect of addition of cysteine was to reduce inorganic $\mathrm{As}(\mathrm{V}), \mathrm{DMA}(\mathrm{V})$ and $\mathrm{MA}(\mathrm{V})$ to the $\mathrm{As}(\mathrm{III})$ state as organo-sulfur-arsenic(III) compounds through the reaction of between the As species and the thiol. These organosulfur derivatives of As(III) more readily react with $\mathrm{NaBH}_{4}$, thereby reducing the $\mathrm{pH}$ dependence of the generation of arsenic hydride species.

HG-AFS is preferred over GF-AAS due to its better sensitivity for arsenic determination [91]. A flow injection (FI)-HG-AAS is recognised as relative simplicity and high sensitivity analytical technique, generally regarded as a suitable technique for As determination in urine $[30,90]$. Other advantages of the technique include excellent sample throughput, reduced sample size, decreased possibility of sample contamination. It is also less prone to interfering elements in comparison with batch mode operation [92]. HG-AFS has outstanding advantages such as excellent sensitivity, relatively interference free, less memory effects, wide linear range, and lower background signal. The high excitation energy of AFS and therefore, high fluorescence response from an analyte, result in a low detection limit [93]. These advantages are mentioned in Table 2.

The vast majority of the studies on As in human urine conducted using HG techniques have focused on experimental ingestion, occupational, and environmental, exposure and ethnicity/genetics. HG-AAS is the most widely used method, with relatively few studies employing HG-AFS. 
HG-AAS/AFS are selective techniques because they only can detect hydride forming As compounds (As(III), As(V), MA, DMA, TMAO and arsenosugars) [86], which prevent them from detecting nonhydride forming As compounds such as $\mathrm{AB}, \mathrm{AC}$ and $\mathrm{Me}_{4} \mathrm{As}$.

\subsubsection{Application of HG-AAS/AFS for urine analysis}

(i) Relationship between arsenic metabolism and genetics/ethncity

Few studies have been conducted on ethnicity and these have focused on exposed populations $[19,94,95]$. On the basis of these studies it has been suggested that ethnic differences may play a role in As metabolism and this may be due to the presence of genetic polymorphism. The relative proportions of urinary As metabolites with respect to As exposure and ethnicity have been investigated by HopenhaynRich et al. [94]. HG-AAS was used (based on a method previously used by Gonsebatt et al. [96]) to test the hypothesis that As metabolism varies among different population. The study was conducted with populations exposed to different levels of As in their drinking water residing in three different countries (Chile, China and Mexico). Urine samples were collected from 292 volunteers from Mexico (112 were exposed to $29 \mu \mathrm{g} / \mathrm{l}$ arsenic in water and 180 were exposed to $408 \mu \mathrm{g} / \mathrm{l}$ arsenic in water), 21 volunteers from Chile (9 were exposed to $21 \mu \mathrm{g} / \mathrm{l}$ arsenic in water and 12 were exposed to $593 \mu \mathrm{g} / \mathrm{l}$ arsenic in water) and 37 volunteers from China (27 were exposed to $18 \mu \mathrm{g} / \mathrm{l}$ arsenic in water and 10 were exposed to $405 \mu \mathrm{g} / \mathrm{l}$ arsenic in water). The level of As species in urine samples (inorganic As, MA and DMA) was in the range of 51.2-961.0 $\mu \mathrm{g} \mathrm{As} / \mathrm{g}$ creatinine for the different populations. Groups exposed to high level of As in their drinking water had up to of 5-10 fold more As in their urine compared to the corresponding low-exposure groups. Differences in the distribution of As metabolites such as ratios of DMA to inorganic As and to MA was observed among the ethnic groups. On the basis of these results the authors [19] suggested that differences in methylation of As in different populations may be related to the presence of genetic polymorphisms within their methylation genes [19].

\section{(ii) Understanding arsenic metabolism through experimental ingestion studies}

Several studies investigating As speciation after experimental ingestion of arsenic containing foodstuff have been performed using HG-AFS. In a study conducted by Le and Ma [97] the validity of using DMA as a biomarker to assess human exposure to inorganic As was discussed. A reversed-phase column C18 phenomenex ODS-3 $(250 \times 4.6 \mathrm{~mm})$ with the mobile phase: $5 \mathrm{mM}$ tetrabutylammonium chloride and $4 \mathrm{mM}$ malonic acid ( $\mathrm{pH}$ 6.0) was used for As speciation in urine samples. The study was performed by asking four volunteers to ingest seaweed, which is known to be a rich source of arsenosugar. An increased concentration of DMA was observed in urine due to metabolism of the arsenosugar. The authors concluded that the use of DMA as a biomarker for assessing human exposure to inorganic As cannot be relied upon if the person ingested arsenosugar-containing seaweed [97].

To determine the baseline level of As in human urine so that it can be used in toxicological studies, HG-AAS was used to analyse urnine from 35 unexposed Japanese volunteers [98]. The dietary intake of each As species was determined alongside the urinary levels of each As species in healthy volunteers (Japanese). Urine samples were collected from the 35 volunteers after they were all fed breakfast, lunch, dinner and a snack between meals. The contents of each meal was classified and weighed. The average of total As in urine was found to be $129 \mu \mathrm{g}$ As/l; the distribution of species consisted of $64.6 \%$ TMA(trimethylated arsenic), 26.7\% DMA, 6.7\% inorganic As and 2.2\% MA [99]. It is noteworthy that they found a significant correlation between urinary TMA and the whole-blood TMA levels.

(iii) Arsenic metabolism in exposed groups - Exposure through diet and environment

Occupational exposure studies have used HG-AAS to investigated As exposures from smelting of non-ferrous metals, glass making, pesticide manufacture, and As refining and production. Hakala and 
Pyy [100] carried out a study with occupational workers from a copper smelting plant and an As trioxide refinery by using HG-AAS. They found that DMA was poorly correlated with exposure, which suggest that increasing concentration of DMA detected in the urine samples analysed is likely to be diet-related [100]. This highlights the fact that DMA is a not a reliable biomarker of arsenic exposure.

The amount of As in ground water used as drinking water, and its health effect, has been investigated among the populations of Jangali (arsenic affected area), West Bengal, using HG-AAS [101-104]. High percentage (77.8\%) of the 1916 water samples that were analysed had As levels above $10 \mu \mathrm{g} / \mathrm{l}$ (WHOrecommended As in drinking water) with $17 \%$ of the samples having As concentration above $300 \mu \mathrm{g} / 1$. The average of total As was $155 \mu \mathrm{g} / \mathrm{l}$ in urine samples of 501 volunteers, which was very high compared to unexposed groups (5-40 $\mu \mathrm{g} / 1.51$ /day). This suggested that the population in this area have an unusually high As body burden [105].

Le et al. [106] used HG-AFS for analysis of urine from 41 volunteers from Mongolia in China, who were exposed to As through their drinking water that contained As at 510-660 $\mu \mathrm{g} / \mathrm{l}$. The volunteers were asked not to consume seafood prior and during the sample collection period. Urine samples were collected and stored at $-20^{\circ} \mathrm{C}$ for approximately 6 months and thawed at room temperature prior to analysis with HG-AFS. The speciation of As species in urine was carried out using HPLC combined with HG-AFS; reversed-phase C18 column (ODS-3, $150 \times 4.6 \mathrm{~mm}$ ), with a mobile-phase solution ( $\mathrm{pH}$ 5.8-5.9) containing $5 \mathrm{mM}$ tetrabutylammonium hydroxide, 2-5 mM malonic acid, and 5\% methanol. The authors detected MA(III) in human urine, which may be explained by stepwise reduction of As(V) to As(III) species followed by oxidative addition of a methyl group to As, according to the Challenger pathway (Fig. 1). The urine samples were measured for As before and after administration of $300 \mathrm{mg}$ of sodium 2,3-dimercapto-1-propane sulfonate (DMPS). They concluded that DMPS possibly assisted the release of MA(III) that was formed in the body, based on their finding that MA(III) in urine samples did not occur from the reduction of MA by DMPS [106].

The effect of diet on As metabolism in humans was investigated by relating dietary intake with urinary As metabolites among 87 exposed volunteers in the western United States [107]. The urinary As metabolites were measured by HG-AAS following a method described by Crecelius [108] The authors concluded that subjects with lower protein intake excreted higher proportion of ingested inorganic As as MA and lower DMA compared with subjects with higher protein intake [107].

\subsection{Graphite furnace - atomic absorption spectrometry (GF-AAS)}

\subsubsection{Basic theory}

The measurement of a reduced intensity of electromagnetic radiation from a light source after its passage through a tube containing gaseous atoms is known as atomic absorption. The terms atomic absorption spectroscopy and absorption spectrometry are often used interchangeable, although the former refer to the study of fundamental principles of atomic absorption while the latter refers to use of the atomic absorption for the quantitative determination of elements in samples [109].

In atomic absorption spectrometry (AAS) the light absorbed by atoms of the analyte is proportional to the number of unexcited atoms present. This has been referred to as Lambert Law and can be expressed in the following equation [110]:

$$
A=a b c,
$$

where: $A=$ absorbance, $a=$ absorption coefficient, $b=$ length of the absorbance path, $c=$ concentration of absorbing atoms. 
From the above equation if $a$ and $b$ are kept constant, then $A$ is directly proportional to $c$, which is an ideal case of the Lambert Law.

In GF-AAS analysis, the sample is heated in a graphite furnace until the element atomizes. To analyse As in urine samples, the sample should be diluted, mixed with a matrix modifier, then the mixture is dried, ashed, and finally atomized at an appropriate temperature. The best performance of GF-AAS for As analysis is achieved using a wavelength of $193.7 \mathrm{~nm}$ with Zeeman background correction. The splitting and polarization of atomic spectral lines in the presence of a magnetic field is called the Zeeman effect. The magnetic field does not affect molecules and particulates in the matrix which causes background absorption. With the magnetic field off the total absorbance is measured and with magnetic field on only the background is measured [111]. A liquid sample $(5-100 \mu \mathrm{l})$ is introduced directly into the tube, using an autosampler. The graphite tube is held in place between two electrodes and aligned with the optical path in AAS instrument, as shown in Fig. 6 [112].

The graphite tube has disadvantages such as porosity and a tendency for carbide formation. These could be overcome by coating the tube with pyrolytic graphite, by heating the tube in a methane atmosphere. Also the tube could be coated with lanthanum to help reduce carbide formation [112]. By programming the supply power controlling the temperature of the furnace, three steps can be carried out automatically on the sample, namely drying, ashing and atomization, each at their particular temperatures. Chemical interference also is one of the disadvantages of the GF-AAS and can lead to analyte loss, which occurs when halides are present because of their volatility. Therefore, it is essential to add a chemical modifier to stabilize the analyte during atomization temperature by forming intermetallic compound such as As-Ni. The addition of nitric acid to the sample (urine) will help form hydrogen chloride (urine contains varying up to $1 \%$ amounts of sodium chloride) [113], which will boil off during the atomization. Background correction is even more essential with furnace atomization, because of the matrix effect, which could be reduced during the ashing step. An inert gas such as nitrogen or argon is used to purge the furnace. Argon is preferred to nitrogen as purge gas because it has less diffusion rate, which results in a larger signal while nitrogen forms nitrides with certain elements such as Ti, $\mathrm{V}$ and Ba.

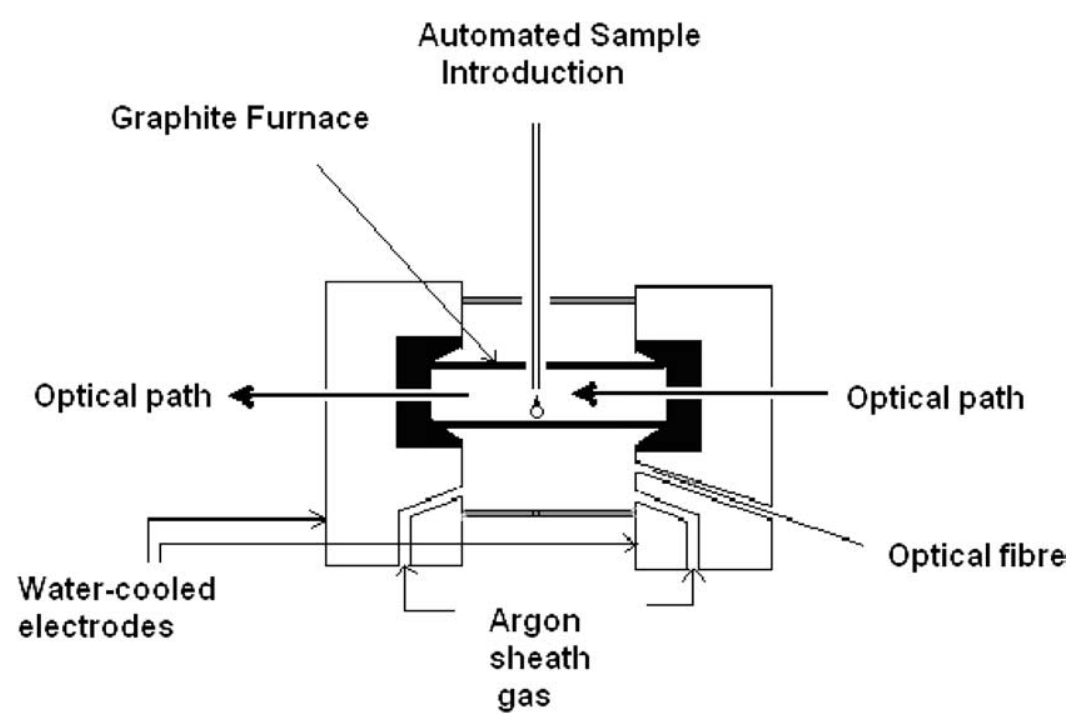

Fig. 6. Schematic diagram describing the typical set-up of a GF-AAS instrument. 
For precision improvement and short time analysis, the atomizer is cooled with water [112]. Further details regarding the background theory of GF-AAS may be obtained from [109].

One of the key advantages of GF-AAS is that little sample preparation is required. A major disadvantage, however, is that As speciation cannot be carried out using a basic GF-AAS setup and thus it can only used for determination of total As.

\subsubsection{Application of GF-AAS for urine analysis}

Different applications of GF-AAS are discussed; one of these applications is a method that used a silica-based solid phase extraction (SPE) strong cation exchange (SCX) cartridge to remove non-toxic organic arsenic compounds ( $\mathrm{AB}$ and $\mathrm{AC}$ ) before determining the total of the toxic arsenic [114].

\section{(i) Arsenic metabolism in exposed groups - Environmental and occupational exposure}

Environmental exposure to As has been investigated by analysing urine samples from healthy volunteers recruited from Barcelona, Spain. Urine samples were collected from 80 volunteers, and were analysed by using GF-AAS; Ni/Mg modifier was used to obtain consistent analysis. A solvent extraction method was used to extract non-toxic As species (AB) from toxicologically relevant arsenic species (As(III), As(V), MA and DMA). The average of total As in urine was $43.3 \mu \mathrm{g} / \mathrm{l}$. The finding of this study was that As levels in men $(53.2 \mu \mathrm{g} / \mathrm{l})$ were significantly different from women $(32.8 \mu \mathrm{g} / \mathrm{l})$. In addition, they confirmed that higher percentage (79\%) of excreted As in urine originated from seafood [57].

In order to assess occupational and environmental exposure to As, urine samples from volunteers working at a coal-fired plant (ENO, Slovakia), were analysed using GF-AAS. The samples were stored at $-18^{\circ} \mathrm{C}$ for several months, and thawed at room temperature prior to analysis. The urine samples were also subjected to solvent extraction prior to analysis, as described elsewhere by Subramanian et al. [115] and the adapted method was as follows: " $12 \mathrm{ml}$ of concentrated $\mathrm{HCl}$ and $0.4 \mathrm{ml}$ of $40 \%$ KI was added to $2.5 \mathrm{ml}$ of urine $12 \mathrm{ml}$ of $\mathrm{HCl}$ and $0.4 \mathrm{ml} 40 \%(\mathrm{~m} / \mathrm{v}) \mathrm{KI}$ were added to $2.5 \mathrm{ml}$ of urine in a reparatory funnel. Then the mixture was shortly mixed and let stand for $60 \mathrm{~min}$. Subsequently $5 \mathrm{ml}$ of toluene $\left(\mathrm{C}_{7} \mathrm{H}_{8}\right)$ saturated by $\mathrm{HCl}$ was added and the reparatory funnel was shaken for $3 \mathrm{~min}$. The emulsion was decomposed by the addition of $0.4 \mathrm{ml}$ of ethanol $\left(\mathrm{C}_{2} \mathrm{H}_{6} \mathrm{O}\right)$. A $3 \mathrm{ml}$ portion of the $\mathrm{C}_{7} \mathrm{H}_{8}$ layer was transferred to the test tube. Arsenic was then re-extracted into $1.5 \mathrm{ml}$ of $0.1 \%$ nickel nitrate in $1 \% \mathrm{HNO}_{3}$ during 1 min and the $\mathrm{Ni}-\mathrm{HNO}_{3}$ layer was taken to AAS analysis". From 465 analyses of arsenic in urine samples, the average urinary total arsenic was $27.1 \mu \mathrm{g} / 1$, which was considered as the sum of As(III), As(V), MA and DMA. The maximum and median values were 256.9 and $19.1 \mu \mathrm{g} / \mathrm{l}$, respectively. Efficiency and accuracy of the arsenic concentration in urine samples were evaluated by analyses of the SRM 2670, and internal reference material-spiked frozen urine, which gave recovery percentages in the range of $98-109 \%$, and $98-103 \%$, respectively. This showed that this method is reliable for environmental and occupational assessment [116].

\subsection{Liquid chromatography-mass spectrometry (LC-MS)}

\subsubsection{Basic theory}

Non-volatile and/or labile compounds are amenable to LC-MS analysis. However, because the gasphase ionisation (electron impact and chemical ionisation) requires thermal volatilisation of the sample, considerations should be given to liquid-phase ionisation such as electrospray ionisation (ESI). Thus in the LC-MS interface and/or ion source only volatile buffers are used such as ammonium acetate, ammonium formate, ammonium hydroxide and acetic trifluoroacetic acid [117].

Mass spectrometry is used to provide information about molecular weight of the analyte, which is introduced into the ionization source. The mass spectrometer can be divided into three parts, namely 


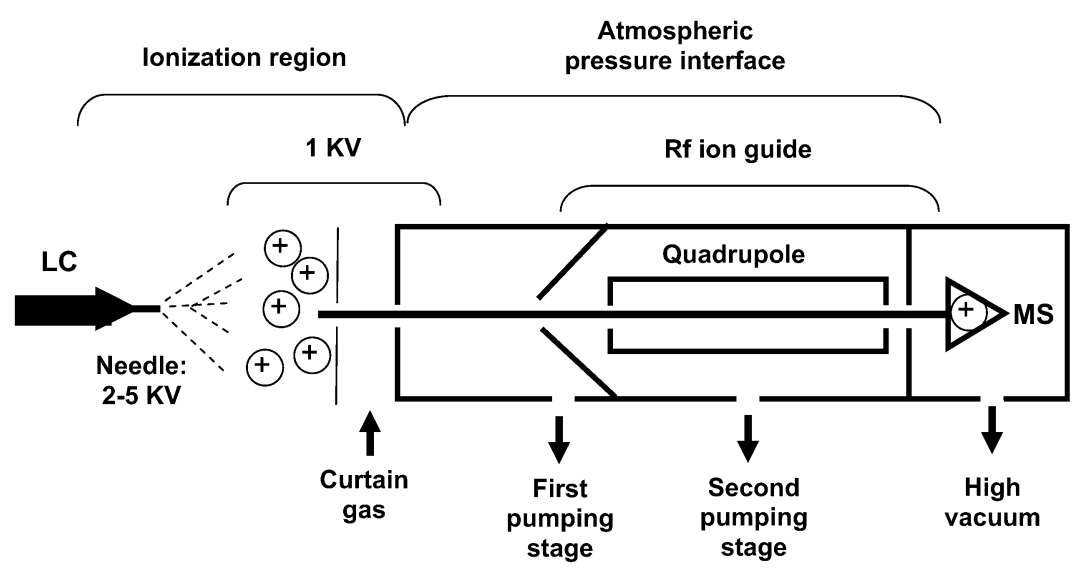

Fig. 7. Schematic diagram of LC-MS.

the ionisation source, the analyser and the detector. The ionised molecules are repelled towards the analyser region of the mass spectrometer where they separate according to their mass-to-charge $(\mathrm{m} / z)$ ratios [118]. Figure 7 shows a schematic diagram of the LC-MS.

To identify unknown compounds, quantify the known materials and elucidate the structure, mass spectrometry is the best technique to be used. It can deal with very small amounts of the analyte, such as 10 to 12 picograms, which makes it the best choice to be used for analysis. The type of analyte determines which mode of the ionisation to be used [119]. The analyte converts into the gas phase either before or during the charging or ionisation process in the ionisation source, which is then introduced into the mass spectrometer under high vacuum $\left(10^{-5} \mathrm{mBar}\right)$. The ionised molecule ion may fragment, producing ions of lower mass than the original molecule. The ionised ions accelerate towards the analyser after being repelled out of the ion source. Only one polarity is chosen, either positive or negative, for analysis although both of them may be generated at the same time. In the analyser, ions that enter the field, experience a deflecting force, depending on the strength of the field and the $\mathrm{m} / z$ ratio of the ion. One sweep of the field strength is defined as scan. For example, an electro-magnet scanned from high to low field will focus, sequentially at the detector, ions of high $\mathrm{m} / z$ ratio down to ions of low $\mathrm{m} / z$ ratio. The detector thus sees ions of varying intensity appearing at certain times during the scan depending on the range and speed of the scan. The time and intensity information is sent to data system where they are converted to $m / z$ ratios and ion abundances, respectively. The pattern obtained is called a mass spectrum [119]. The most sensitive detection mode of a single quadrupole is known as selected ion monitoring (SIM), in which a single $m / z$ will be monitored at maximum collection efficiency and sensitivity. Typically, there are two orders of magnitude sensitivity difference between scanning and SIM modes [120].

Electrospray ionisation (ESI) is an atmospheric pressure ionisation technique. After the sample is dissolved in a mobile phase containing a mixture of water and acetonitrile or methanol, it is pumped through a stainless steel capillary at atmospheric pressure; the tip is floated at high potential $(3-4 \mathrm{kV})$ relative to a counter electrode. Multiple charged droplets containing the analyte are created, because the high potential and a stream of nitrogen gas (nebulising gas) assists the spray process [119]. Figure 7 shows the formations of multiply charged ion in ESI. Gas phase ions are produced and propelled towards the high vacuum analyser after desolvation and subsequent charge concentration. ESI is the softest ionisation technique, because little energy is transferred to the molecule other than that required for ionisation. Therefore, protonated, deprotonated or cationised molecules that undergo very little fragmentation are generated even from highly polar, thermal labile molecules. The ions generated from large 
molecules are frequently multiply charged, yielding a complex mass spectrum, which when transformed to a simple one, reveals the molecular weight of the analyte [119]. A book by Willoughby et al. [120] is recommended for further reading on the background theory of LC-MS.

The advantage of LC-ESI-MS is that can be used for structure confirmation, but with the disadvantage that it has a high limit of detection and is affected by the urine matrix. LC-ESI-MS has more advantages such as providing qualitative information about organoarsenic compounds with the absence of standards. LC-ESI-MS also provides quantitative data for As compounds that chromatography can not be resolved. The other advantage for this technique is that it provides structural information about unknown As compounds [121].

LC-MS is affected by the sample matrix which leads to a suppression of its sensitivity. This problem has been overcome in our lab by using a strong cation exchange solid phase extraction (SCX SPE) cartridge to remove the matrix effect and to extract $\mathrm{AB}$ from human urine prior to analysis by LC-ESIMS. This has been done with a slight modification, following published protocol for As fractionation using SCX SPE by Nixon and Moyer [114]. As a result the sensitivity of the technique was increased with almost three times as shown in Fig. 8, which was carried out in our laboratory. A urine sample was spiked with $282 \mu \mathrm{g} \mathrm{As} / \mathrm{l}$ of $\mathrm{AB}$ then diluted $(1: 10)$ with $1 \% \mathrm{v} / \mathrm{v} \mathrm{HNO}_{3}$. The spiked urine sample was divided into two portions: first portion of this urine sample was put through a LC-ESI-MS system before using a SCX SPE cartridge. The second portion was passed through a SCX-SPE cartridge and then put through a LC-ESI-MS system. A pure standard of AB (25 $\mu \mathrm{g} \mathrm{As} / \mathrm{l})$ was put through a LC-ESIMS system, without passing it through SCX SPE cartridge. This was to show how a urine matrix can

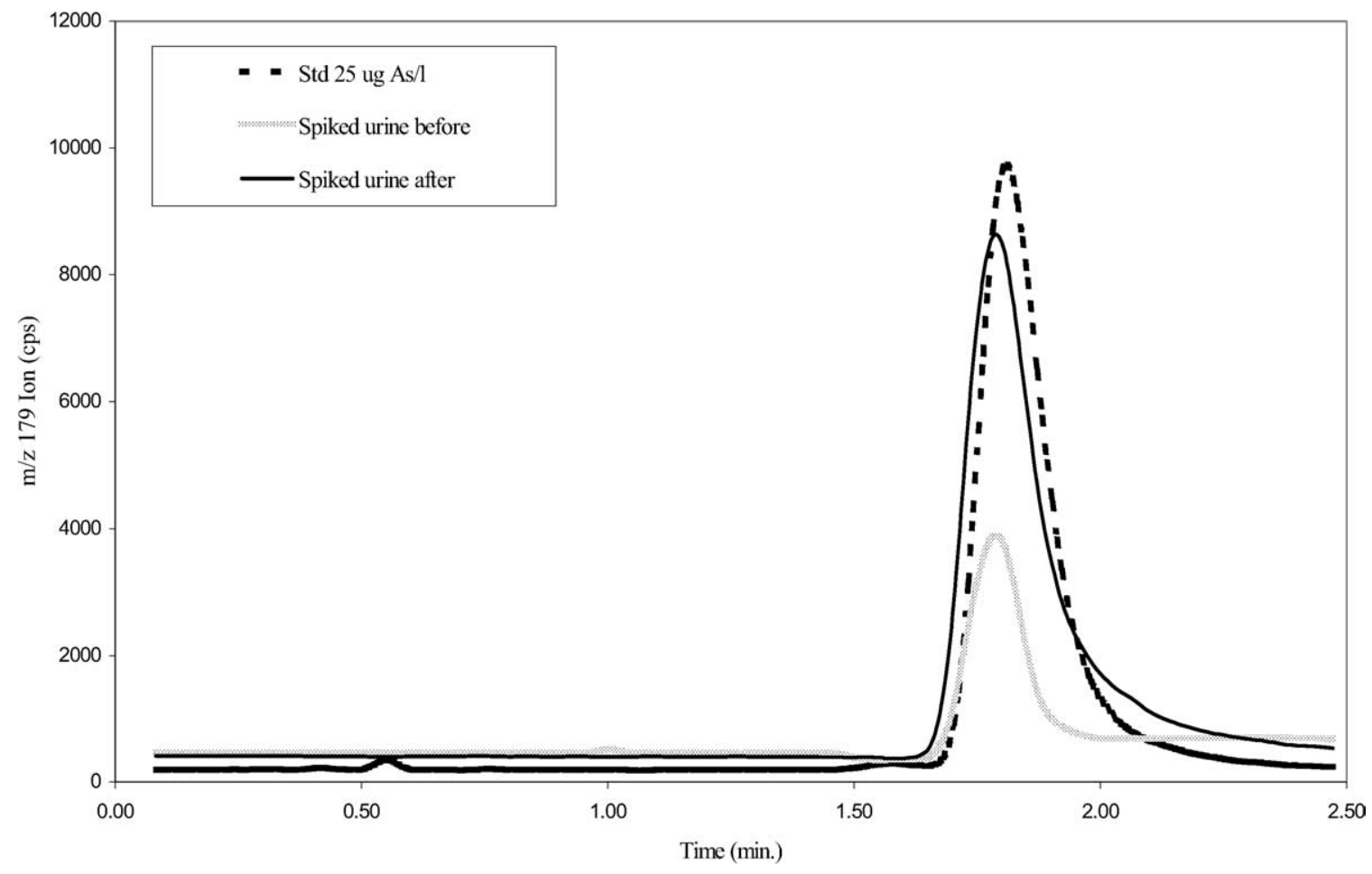

Fig. 8. Overlaid LC-MS chromatograms for the analysis of diluted (1: $10 \mathrm{w} / \mathrm{w}$ ) human urine spiked with $282 \mu \mathrm{g} \mathrm{As} / 1$ of AB before and after using SPE cation exchange for matrix removal. Also included in the chromatogram AB standard (25 $\mu \mathrm{g}$ As/l) prepared in $1 \% \mathrm{v} / \mathrm{v} \mathrm{HNO}_{3}$. 
influence the sensitivity of LC-ESI-MS system, and how the sensitivity can be increased by using a SCX SPE cartridge.

The SCX SPE (Phenomenex, USA) Strata SCX (500 mg/3 ml) was used for AB extraction and clean up. The SPE involves 5 steps, which were modified from a previously published method [114], and they are as follows: (1) conditioning step with methanol ( $3 \mathrm{ml})$; (2) an equilibration step with deionised water (3 ml); (3) loading the diluted (1:10) urine with $1 \% \mathrm{v} / \mathrm{v} \mathrm{HNO}_{3}(3 \mathrm{ml})$; (4) a washing step with $2 \% \mathrm{v} / \mathrm{v}$ $\mathrm{HNO}_{3}$; and (5) elution with $1.75 \% \mathrm{v} / \mathrm{v} \mathrm{NH} \mathrm{NH}_{4} \mathrm{OH}(3 \mathrm{ml})$. In the last step (5), the extract which contains cationic As species (e.g. AB) is a collected in a tube and measured by SIM at $m / z[\mathrm{M}+\mathrm{H}]^{+} 179$, using LC-MS.

\subsubsection{Application of LC-MS for urine analysis}

(i) Understanding arsenic metabolism through experimental ingestion studies, and identifies new compounds by structural confirmation

A new arsenosugar metabolite (dimethylarsinoylacetate (DMAA)), besides previously reported metabolites (DMA and dimethylarsinoylethanol (DMAE)), was identified in urine of a sheep that ingest more than $30 \mathrm{mg}$ arsenic/day as arsenosugar. This identification was reported by Hansen et al. [122], using a combination of HPLC-ESI-MS and HPLC-ICP-MS. An interesting aspect of this finding is that the metabolism of arsenosugars in the sheep is similar to that in human; it is noteworthy that DMA is a major metabolite in human after arsenosugar ingestion [123]. An ingestion experiment was carried out in human by Francesconi et al. [123] in which a volunteer ingested $1220 \mu \mathrm{g}$ As (in $25 \mathrm{ml}$ water) of a pure synthesized arsenosugar (dimethylarsinoylriboside derivatives, molecular weight $=328$ where $\times=\mathrm{OH}$, see Table 1). After 4 days of ingestion, $80 \%$ of total ingested arsenic was excreted in urine and 12 metabolites were detected, only three of them were identified. The identified compounds percentages of the total excreted arsenicals were 67\% DMA, 5\% DMAE and $0.5 \%$ TMAO. This finding confims the biotransformation of pure arsenosugar by humans to well-known organoarsenic compounds alondside different unknown metabolites. Furthermore, the combination of these techniques has proved to be an excellent tool for identification of new As species. Arsinothioylsugars were reported for the first time after incubation of seaweed extract with liver cytosol [124]. This finding suggested the presence of these sulfur-containing As compounds was overlooked due to a lack of suitable analytical methods, therefore more of these compounds may be identified in the future, as stated by Feldmann and co-authors [124]. More investigations by the same group led to a conclusion that a sulfur-containing arsenic (dimethylarsinothioic acid (DMAS)) compound was mistakenly identified as DMA(III) in urine [125]. More applications of HPLC-ESI-MS for As speciation in urine have been reported; AB and DMA have been measured in human urine [126], and TMAO was identified in urine of rats chronically exposed to DMA [127]. The purpose of both studies was to evaluate the capability of this technique for quantification and identification of organoarsenic compounds in urine.

\section{Summary}

The summary of findings of the case studies highlighted in this review in terms of the three main fields - As metabolism in humans as a function of genetics/ethnicity, experimental ingestion studies and exposure to As - are as follows: 
It appears that ethnicity plays a role in differences observed in total As and As species among various groups irrespective of these populations being exposed or unexposed to As in their drinking water. Genetic polymorphism has been suggested to be a factor that may explain these differences. Further studies with a larger population size, carefully controlled diet, and genetic analysis needs to be carried out in order to pinpoint the precise reason for the observed differences between various ethnic groups.

By far the greatest number of studies has focused on population exposed to As in their drinking water. These studies have revealed a positive correlation between As concentration in drinking water and total As in urine. Among such exposed groups there are variations in As metabolism, and arsenicosis, which can be related to gender, age and diet. For example, children show less skin lesion, which was attributed to a higher capacity of their second methylation step compared to adults. In addition to this, females show higher urinary DMA levels than males, which was explained as being due to greater methylation efficiency in women than men. Regarding diet association with As metabolism it was confirmed that percentage of urinary DMA is positively correlated with protein and folate intake in population exposed to As in their drinking water.

Various ingestion studies have been useful for understanding As metabolism through identification of metabolites excreted in urine. For example, DMA was found to be a major metabolite in urine after ingestion of arsenosugar and foods containing arsenolipids, highlighting the need to exercise caution when using the level of DMA as an indicator of toxic As exposure. The ingestion study with cod liver, which contains arsenolipids, resulted in the identification of four novel arsenic species in the urine of the volunteers. However, much more work needs to be done to identify several different unknown metabolites that were detected in human urine after arsenosugars, arsenolipids and seaweed ingestion.

With respect to methodology, hyphenated techniques involving a highly efficient separation and a highly sensitive detection have become the techniques of choice for analysis of As in urine, especially ICP-MS. HPLC separation with HG atomic spectrometry techniques have been the most useful approach for As speciation in urine samples, particularly for toxicologically relevant As compounds. Structural identification is essential and a complementary task for exploring new metabolites, in which ESI-MS considered the only technique to be used for detection. When choosing a sensitive and reliable method for total and As speciation in urine, the experimentalist needs to be aware of the advantages and disadvantages of each technique and select the most appropriate method based on the level and type of As species that needs to be determined.

The techniques used for quantification, separation and detection discussed in this review have their respective advantages and disadvantages regarding the total level of As and As species distribution in urine. Sample pre-treatment is a main disadvantage in all techniques involved in the determination of As in human urine. It is hoped that future instrumental development will facilitate removal of this step, leading to more efficient and faster analysis of As in human urine. Progress in our understanding of As metabolism in human populations is not just limited by technology but by other factors as well. For example, difficulties encountered in recruiting sufficient number of healthy/exposed volunteers, and at the same time adequately control all the variables such as diet, lifestyle patterns, etc., makes it all the more challenging.

\section{Acknowledgement}

De Montfort University is thanked for granting a PhD studentship to Eid I. Brima. 


\section{References}

[1] G. Samanta, T. Roychowdhury, B.K. Mandal, B.K. Biswas, U.K. Chowdhury, G.K. Basu, C.R. Chanda, D. Lodh and D. Chakraborti, Microchem. J. 62 (1999), 174-191.

[2] H. Tokunaga, T. Roychowdhury, N. Chandraskaran, T. Uchino and M. Ando, Appl. Organometal. Chem. 16 (2002), 406-414.

[3] G. Samanta, U.K. Chowhhury, B.K. Mandal, D. Chakraborti, N.C. Sekaran, H. Tokunaga and M. Ando, Microchem. J. 65 (2000), 113-127.

[4] X.C. Le, W.R. Cullen and K.J. Reimer, Clin. Chem. 40 (1994), 617-624.

[5] X.C. Le and M. Ma, J. Chromatogr. A 764 (1997), 55-64.

[6] X.C. Le, W.R. Cullen and K.J. Reimer, Anal. Chim. Acta 285 (1994), 277-285.

[7] E.H. Larsen, G. Pritzl and S.H. Hansen, J. Anal. At. Spectrom. 8 (1993), 557-563.

[8] F. Challenger, Chem. Rev. 36 (1945), 315-362.

[9] T. Hayakawa, Y. Kobayashi, X. Cui and S. Hirano, Arch. Toxicol. 79 (2005), 183-191.

[10] M. Vahter, Toxicology 181 (2002), 211-217.

[11] M. Ma and X.C. Le, Clin. Chem. 44 (1998), 539-550.

[12] K.A. Francesconi, R. Tanggaard, C.J. McKenzie and W. Goessler, Clin. Chem. 48 (2002), 92-101.

[13] V.M. Hulle, C. Zhang, B. Schotte, L. Mees, F. Vanhaecke, R. Vanholder, X.R. Zhang and R. Cornelis, J. Anal. At. Spectrom. 19 (2004), 58-64.

[14] K. Wrobel, B. Parker, S.S. Kannamkumarath and J.A. Caruso, Talanta 58 (2002), 899-907.

[15] J. Feldmann, V.W. Lai, W.R. Cullen, M. Ma, X. Lu and X.C. Le, Clin. Chem. 45 (1999), 1988-1997.

[16] M. Ricardo, M. Valeria, H. Alba, C. Amadeu, S. Chandra, T. Hiroshi and Q. Domingo, J. Occup. Environ. Med. 48 (2006), 334-341.

[17] H. Chiou, Y. Hsueh, L. Hsieh, L. Hsu,Y. Hsu, F. Hsieh, M. Wei, H. Chen, H. Yang, L. Leu, T. Chu, C. Chen-Wu, M. Yang and C. Chen, Mutat. Res. 386 (1997), 197-207.

[18] H.V. Aposhian and M.M. Aposhian, Chem. Res. Toxicol. 19 (2006), 1-15.

[19] C.A. Loffredo, H.V. Aposhian, M.E. Cebrian, H. Yamauchi and E.K. Silbergeld, Environ. Res. 92 (2003), 85-91.

[20] V.W. Lai, Y. Sun, E. Ting, W.R. Cullen and K.J. Reimer, Toxicol. Appl. Pharm. 198 (2004), 297-306.

[21] E.I. Brima, P.I. Haris, R.O. Jenkins, D.A. Polya, A.G. Gault and C.F. Harrington, Toxicol. Appl. Pharm. (2006) (in press).

[22] R. Ritsema, L. Dukan, T.R. Navarro, W.V. Leeuwen, N. Oliveria, P. Wolfs and E. Lebret, Appl. Organomet. Chem. 12 (1998), 591-599.

[23] X.C. Le and M. Ma, Anal. Chem. 70 (1998), 1926-1933.

[24] P.N. Williams, A.H. Price, A. Raab, S.A. Hossain, J. Feldmann and A.A. Meharg, Environ. Sci. Technol. 39 (2005), 5531-5540.

[25] E.M. Kenyon, L.M. Del Razo and M.F. Hughes, Toxicol. Sci. 85 (2005), 468-475.

[26] J.P. Buchet and R. Lawerys, Inorganic arsenic metabolism in human, in: Arsenic Exposure and Health, W.R. Chappell, C.O. Abernathy and C.R. Cothern, eds, Science and Technology letters, Northwood, 1994, pp. 171-179.

[27] E. Marafante and M. Vahter, Fundam. Appl. Toxicol. 3 (1983), 309-314.

[28] M. Vahter, G. Concha, B. Nermell, R. Nilson, F. Dulout and A.T. Natarajan, J. Pharm. Environ. Toxicol. Pharm. Section 293 (1995), 455-462.

[29] U.K. Chowdhury, M.M. Rahman, M.K. Singupta, D. Lodh, C.R. Chanda, S. Roy, Q. Quamruzzaman, H. Tokunaga, M. Ando and D. Chkraborti, Environ. Sci. A38 (2003), 87-113.

[30] S.M. Lin and C.H. Chiang, Biol. Trace Elem. Res. 8 (1985), 11-18.

[31] J.S. Chung, D.A. Kalman, L.E. Moore, M.J. Kosnett, A.P. Arroyo, M. Beeris, D.N.G. Mazumder, A.L. Hernandez and A.H. Smith, Environ. Health Perspect. 110 (2002), 729-733.

[32] F.S. Islam, A.G. Gault, C. Boothman, D.A. Polya, J.M. Charnock, D. Chatterjee and J.R. Lloyd, Nature 430 (2004), 68-71.

[33] A.G. Gault, F.S. Islam, D.A. Polya, J.M. Charnock, C. Boothman, D. Chattertje and J.R. Lloyd, Mineral Mag. 69 (2005), 855-863.

[34] M. Vahter, Appl. Organomet. Chem. 8 (1994), 175-182.

[35] W. Goessler, C. Schlagenhaufen, D. Kuehnelt, H. Greschonig and K.J. Irgolic, Appl. Organometal. Chem. 11 (1997), 327-335.

[36] J.S. Edmonds, Appl. Organomet. Chem. 12 (1998), 515-517.

[37] L.R. Johnson and J.G. Farmer, Bull. Environ. Contam. Toxicol. 46 (1991), 53-61.

[38] A.L. Hinwood, M.R. Sim, N. de Klerk, O. Drummer, J. Gerostamoulos and E.B. Bastone, Enviromen. Reseach Sec. A 88 (2002), 219-224.

[39] M. Carrieri, A. Trevisan and G.B. Bartolucci, Int. Arch. Occup. Environ. Health 74 (2001), 63-67.

[40] Z. Gong, X. Lu, W.R. Cullen and X.C. Le, J. Anal. At. Spectrom. 16 (2001), 1401-1413. 
[41] Y.C. Chen, C.J. Amarasiriwardena, Y.M. Hsueh and D.C. Christiani, Cancer Epidem. Biomar. 11 (2002), 1427-1433.

[42] J. Yoshinga, A. Chatterjee, Y. Shibata, M. Morita and J.S. Edmonds, Clin. Chem. 46 (2000), 1781-1786.

[43] O.L. Valenzuela, V.H. Borja-Aburto, G.G. Garcia-Vargas, M.B. Cruz, E.A. Garcia-Montalvo, E.S. Calderon-Aranda and L.M. Del Razo, Gonzalez, Environ. Health Perspect. 113 (2005), 250-254.

[44] X.C. Le and M. Ma, Anal., J. Chromatogr. A 764 (1997), 55-64.

[45] S.N. Kales, K.L. Huyck and R.H. Goldman, J. Anal. Toxicol. 30 (2006), 80-85.

[46] J. Zheng, W. Kosmus, F. Pichler-Semmelrock and M. Köck, J. Trace Elem. Med. Biol. 13 (1999), 150-156.

[47] E. David and T.P. Moyer, Spectrochim. Acta B 51 (1996), 13-25.

[48] T.I. Todorov, J.W. Ejnik, F.G. Mulick and J.A. Centeno, Microchim. Acta 151 (2005), 263-268.

[49] M. Moldova, M.M. Gomez, M.A. Palacios and C. Camara, Microchem. J. 59 (1998), 89-99.

[50] X.C. Le and M. Ma, Anal., J. Chromatogr. A 764 (1997), 55-64.

[51] R. Raml, W. Goessler, P. Traar, T. Ochi and K.A. Francesconi, Chem. Res. Toxicol. 18 (2005), 1444-1450.

[52] Y. Shibata, K.T. Suzuku, S. Komori, C. Umedzu, H. Imai and M. Morita, Appl. Organomet. Chem. 19 (2005), $276-281$.

[53] E. Schmeisser, W. Goessler and K.A. Francesconi, Anal. Bioanal. Chem. 385 (2006), 367-376.

[54] M. Vahter, G. Concha, B.O. Nermell, R. Nilson, F. Dulout and A.T. Natarajan, Eur. J. Pharm.-Environ. 293 (1995), $455-462$.

[55] F.J. Heilier, J.P. Buchet, V. Haufroid and D. Lison, Int. Arch. Occup. Environ. Health 78 (2005), 51-59.

[56] X.C. Le and M. Ma, J. Chromatogr. A 764 (1997), 55-64.

[57] M. Torra, J.M. Auge, B. Ballell, M. Rodamilans, C. Casoliva and J. Corbella, Trace Elem. Electroly. 21 (2004), $248-251$.

[58] N. Shimisu, Y. Inoue, S. Daishima and K. Yamaguchi, Anal. Sci. 15 (1999), 685-687.

[59] A.G. Gault, J. Jana, S. Chakraborty, P. Mukherjee, M. Sarkar, B. Nath, D.A. Polya and D. Chatterjee, Anal. Bioanal. Chem. 381 (2005), 347-353.

[60] J. Szpunar, Analyst 130 (2005), 442-465.

[61] C. B'Hymer and J.A. Caruso, J. Chromatogr. A 1045 (2004), 1-13.

[62] M. Montes-Bayón, K. DeNicola and J.A. Caruso, J. Chromatogr. A 1000 (2003), 457-476.

[63] K.A. Francesconi and D. Kuehnelt, Analyst 129 (2004), 373-395.

[64] A. Montaser, Inductively Coupled Plasma Mass Spectrometry, Wiley-VCH Inc., New York, 1998.

[65] S.D. Tanner, V.I. Baranov and D.R. Bandura, Spectrochim. Acta Part B 57 (2002), 1361-1452.

[66] Merriam-Webster's Online Dictionary, 2005.

[67] A. Margaret and M.D. Winker, J. Am. Med. Assoc. 292 (2004), 1612-1614.

[68] E.S. Lander, L.M. Linton and B. Birren, Nature 409 (2001), 860-921.

[69] M.M. Meza, L. Yu, Y.Y. Rodriguez, M. Guild, D. Thompson, A.J. Gandolfi and W.T. Klimercki, Environ. Health Perspect. 113 (2005), 775-781.

[70] K.A. Francesconi, R. Tanggaar, C.J. McKenzie and W. Goessler, Clin. Chem. 48 (2002), 92-101.

[71] H. Matsuura, M. Asano, T. Hasegawa, T. Umemura and H. Haraguchi, Bull. Chem. Soc. 78 (2005), 1977-1981.

[72] C. Wei, W.H. Li, C. Zhang, M. Van Hulle, R. Cornelis, X.R. Zhang, J. Agric. Food. Chem. 51 (2003), 5176-5182.

[73] E. Schmeisser, A. Rumpler, M. Kollroser, G. Rechberger, W. Goessler and K.A. Francesconi, Angew Chem. Int. Ed. Engl. 45 (2006), 150-154.

[74] P.L. Smedley and D.G. Kinniburgh, Appl. Geochem. 17 (2002), 517-568.

[75] G. Sun, Toxicol. Appl. Pharm. 198 (2004), 268-271.

[76] A. Shraim, X. Cui, S. Li, J.C. Ng, J. Wang, Y. Jin, Y. Liu, L. Guo, D. Li, S. Wang, R. Zhang and S. Hirano, Toxicol. Lett. 137 (2003), 35-48.

[77] W.J. Christian, C. Hopenhayn, J.A. Centeno and T. Todorv, Environm. Res. 100 (2006), 115-122.

[78] M.V. Gamble, X. Liu, H. Ahsan, J.R. Pilsner, V. Ilievski, V. Slavkovich, F. Parvez, D. Levy, P. Factor-Litvak and J.H. Graziano, Environ. Health Perspect. 113 (2005), 1683-1688.

[79] N.P. Vela, D.T. Heitkemper and K.R. Stewart, Analyst 126 (2001), 1011-1017.

[80] D. Nixon, G. Mussmann, S. Eckdahl and T. Moyer, Clin. Chem. 37 (1991), 1575-1579.

[81] W.T. Corns, P.B. Stockwell, L.C. Ebdon and S.J. Hill, J. Anal. At. Spectrom. 8 (1993), 71-77.

[82] X.C. Le and W.R. Cullen, Anal. Chimica Acta 258 (1992), 307-315.

[83] Hydride Generation Users Guide Introduction, P S Analytical Ltd., Arthur house, Crayfields Industrial Estate, Orpington, Kent, England.

[84] J. Dedina, Prog. Anal. Atom. Spect. 11 (1988), 251-360.

[85] B. Welz and M. Schubertjacobs, J. Anal. At. Spectrom. 1 (1986), 23-27.

[86] E. Schmeisser, W. Oessler, N. Kienzl and K.A. Francesconi, Anal. Chem. 76 (2004), 418-423.

[87] N.G. Van der Veen, H.J. Keukens and G. Vos, Anal. Chim. Acta 171 (1985), 285.

[88] W.A. Maher, Talanta 30 (1983), 534.

[89] G. Sammanta, Microchem. J. 65 (2000), 113-127.

[90] Methods of Analysis, P S Analytical Ltd., Arthur house, Crayfields Industrial Estate, Orpington, Kent, England. 
[91] R.M. Tripathi, R. Raghunath and T.M. Krishnamoorthy, Sci. Total. Environ. 208 (1997), 89-95.

[92] J.F. Tyson, Spectrochim. Acta Rev. 14 (1991), 169-233.

[93] A. Caballo-López and M.D. Luque de Castro, J. Anal. At. Spectrom. 17(2002), 1363-1367.

[94] C. Hopenhayn-Rich, M.L. Biggs, A.H. Smith, D.A. Kalman and L.E. Moore, Environ. Health Perspect. 104 (1996), $620-628$.

[95] C. Hopenhayn-Rich, M.L. Biggs, D.A. Kalman, L.E. Moore and A.H. Smith, Environ. Health Perspect. 104 (1996), 1200-1207.

[96] M.E. Gonsebatt, I. Vega, L. Salazar, A.M. Montero, P. Guzman, J. Blas, M.L. del Razo, G. Racia-Vargas, A. Albores, M.E. Cebrian, M. Kelsh and P. Ostrosky-Wegman, Mutat. Res. 386 (1997), 219-228.

[97] X.C. Le and M. Ma, Anal. Chem. 70 (1998), 1926-1933.

[98] H. Yamauchi and Y. Yamamura, Toxicol. Appl. Pharm. 74 (1989), 134-140.

[99] H. Yamauchi, K. Takahashi, M. Mashiko, J. Saitoh and Y. Yamamura, Appl. Organomet. Chem. 6 (1992), 383-388.

[100] E. Hakala and L. Pyy, J. Anal. At. Spectrom. 7 (1992), 191-196.

[101] A. Chatterjee, D. Das, B.K. Mandal, T. Roychowdhury, G. Samanta and D. Chakraborti, Analyst 120 (1995), 643-650.

[102] D. Das, A. Chatterjee, B.K. Mandal, G. Samanta and D. Chakraborti. Analyst 120 (1995), 917-924.

[103] G. Samanta and D. Chakraborti, Frenius J. Anal. Chem. 357 (1997), 827-832.

[104] G. Samanta, T. Roychowdhury, B.K Mandal, B.K Biswas, U.K. Chowdhury and G.K. Basu, Microchem. J. 62 (1999), $174-191$.

[105] M.M. Rahman, M.K. Sengupta, S. Ahmed, U.K. Chowdhury, M.A. Hossin, B. Das, D. Lodh, K.C. Saha, S. Pati, I. Kaies, A.K. Barua and D. Chakraborti, Sci. Total Environ. 338 (2005), 189-200.

[106] X.C. Le, M. Ma, X. Lu, W.R. Cullen, H.V. Aposhian and B. Zheng, Environ. Health Perspect. 108 (2000), 1015-1018.

[107] C. Steinmaus, K. Carrigan, D. Kalman, R. Atallah, Y. Yuan and A.H. Smith, Environ. Health Perspect. 113 (2005), $1153-1159$.

[108] E.A. Crecelius, Anal. Chem. 50 (1978), 826-827.

[109] D.J. Butcher and J. Sneddon, A Practical Guide to Graphite Furnace Atomic Absorption Spectrometry, Wiley, 1998.

[110] J.H. Moffett, Varian instruments at work, AA-128, Varian Australia Pty. Ltd. Mulgrave Victoria. February 2000.

[111] Varian spectrAA 220/880 Zeeman brochure, 2003. Available: http//:www.varianinc.com/cgi-bin/find [accessed 18 July 2003].

[112] L. Ebdon, A. Fisher and S.J. Hill, in: An Introduction to Analytical Atomic Spectrometry, E.H. Evans, ed., Wiley, West Sussex, England, 1998, pp. 51-71.

[113] J.K. Norymberski and R.D. Stubbs, Biochem. J. 64 (1956), 176-178.

[114] D.E. Nixon and T.P. Moyer, Clin. Chem. 38 (1992), 2479-2483.

[115] K.S. Subramanian, Can. J. Spectrosc. 33 (1988), 173-181.

[116] D. Borošová1, J. Mocak, E. Beinrohr and P. Miškovič, Pol. J. Environ. Stud. 11 (2002), 617-623.

[117] R. Chapman, Practical Organic Mass Spectrometry: A Guide for Chemical and Biochemical Analysis, 2nd edn, Wiley, West Sussex, England, 1993, p. 50.

[118] A.E. Ashcroft, Ionization methods in organic mass spectrometry, RSC, 1997, pp. 1-22.

[119] Mass spectrometry, 2003. Available: http://www.bmss.org.uk. [accessed 21 July 2003].

[120] R. Willoughby, E. Sheehan and S. Mitrovich, A Global View of LC/MS, 2nd edn, Chem-Space Associates, Inc. Pittsburgh, USA, 2002.

[121] J.S. Edmonds and K.A. Francesconi, Organic compounds in terrestrial environment, in: Organometallic Compounds in the Environment, P.J. Craig, ed., 2nd edn, Wiley, West Sussex, England, 2003, pp. 215-217.

[122] H.R. Hansen, A. Raab and J. Feldmann, J. Anal. At. Spectrom. 18 (2003), 474-479.

[123] K.A. Francesconi, R. Tanggaard, C.J. McKenzie and W. Goessler, Clin. Chem. 48 (2002), 92-101.

[124] H. R. Hansen, M. Jaspars and J. Feldmann, Analyst 129 (2004), 1058-1064.

[125] H.R. Hansen, A. Raab, M. Jaspars, B.F. Milne and J. Feldmann, Chem. Res. Toxicol. Analyst 17 (2004), 1086-1091.

[126] N. Shimizu, Y. Inoue, S. Dashima and K. Yamaguchi, Anal. Sci. 15 (1999), 685-687.

[127] Y. Inoue, Y. Date, T. Sakai, N. Shimizu, K. Yoshida, H. Chen, K. Kuroda and G. Endo, Appl. Organomet. Chem. 13 (1999), 81-88. 


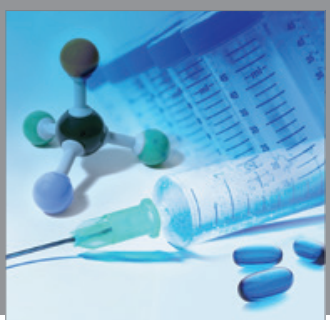

International Journal of

Medicinal Chemistry

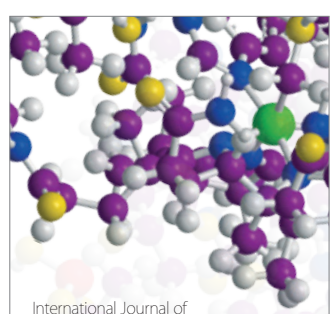

Carbohydrate Chemistry

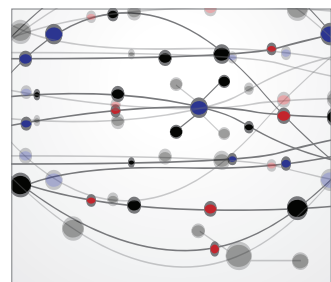

The Scientific World Journal
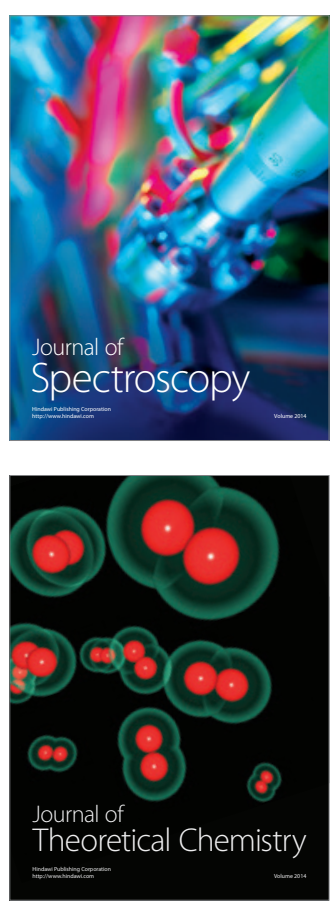
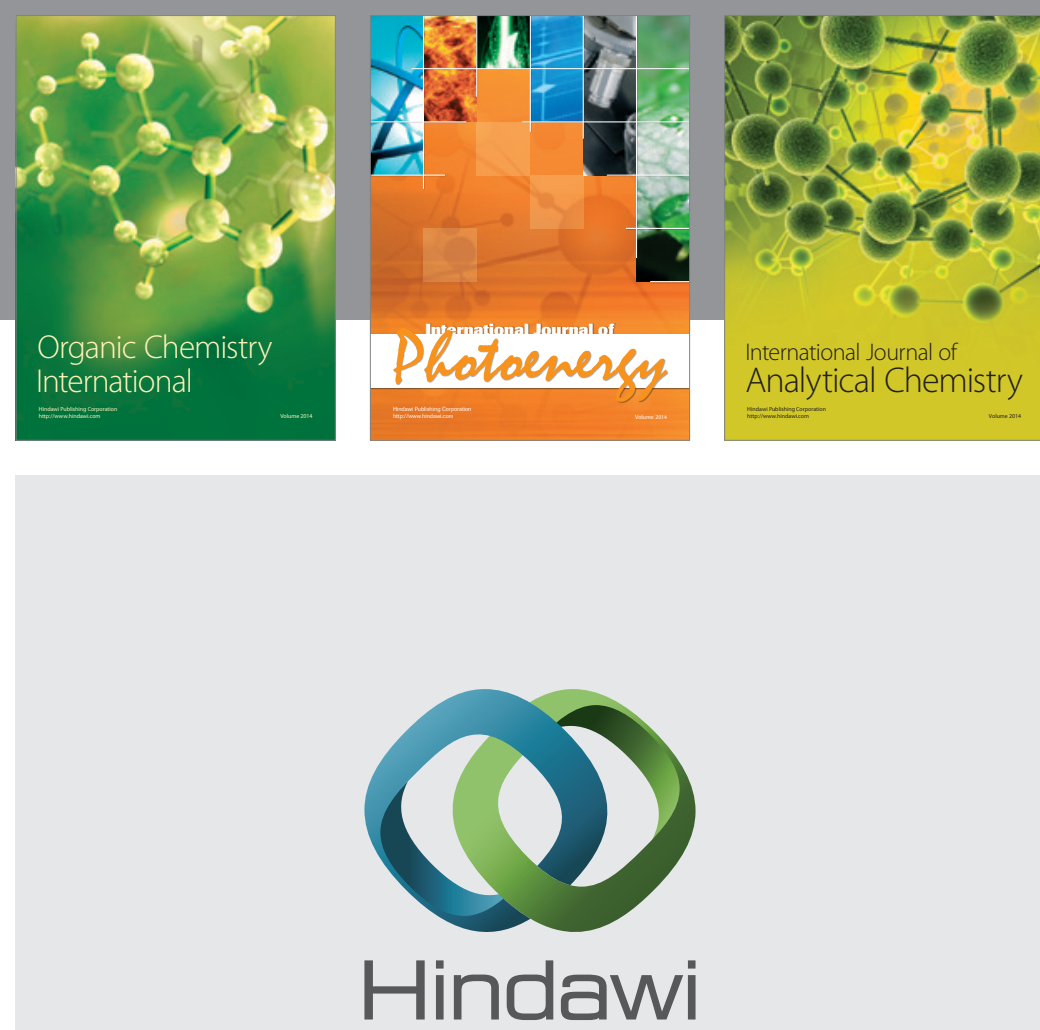

Submit your manuscripts at

http://www.hindawi.com
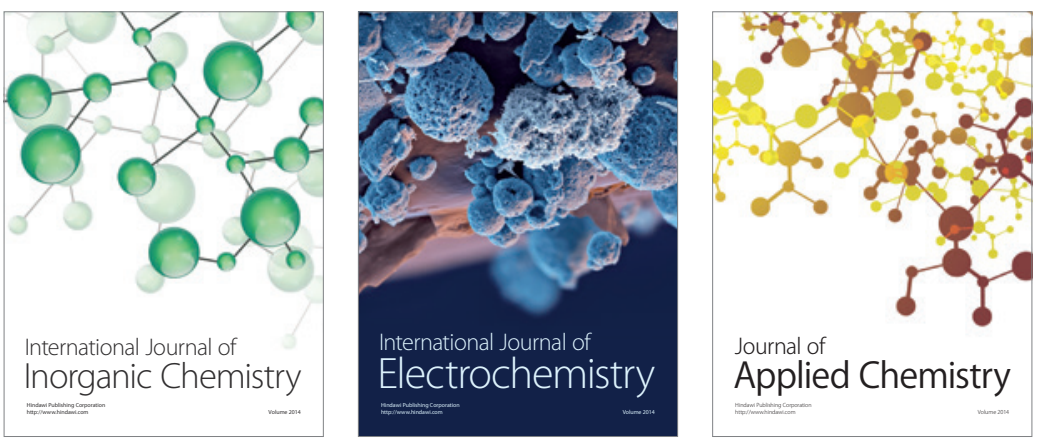

Journal of

Applied Chemistry
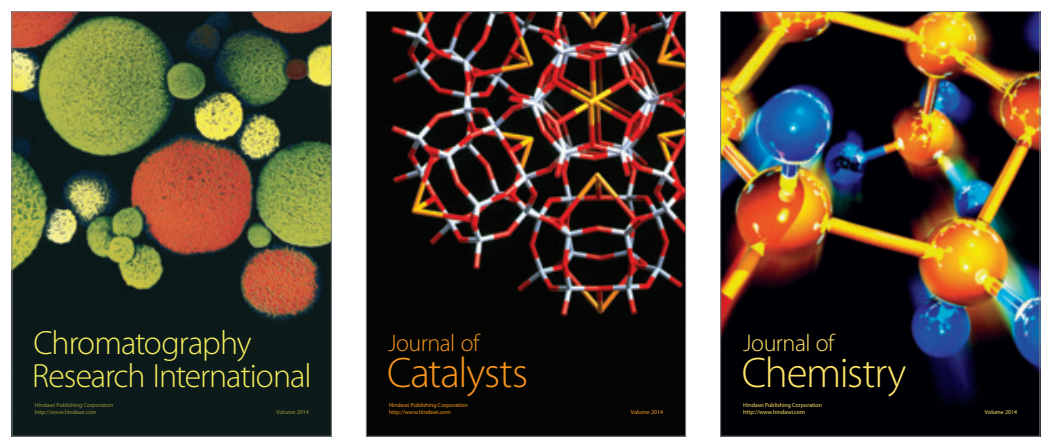
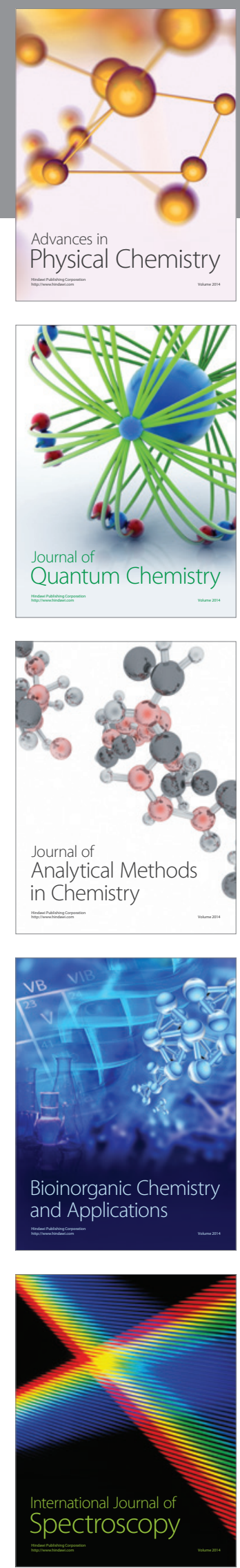